Content-type: Article

\title{
Surface Modified Copper Alloy Powder for Reliable Laser-based Additive Manufacturing
}

\author{
Suraj Dinkar Jadhav a *, Pushkar Prakash Dhekne a , Sasan Dadbakhsh ${ }^{\text {b, c }}$, Jean-Pierre Kruth ${ }^{\text {b }}$, Jan \\ Van Humbeeck ${ }^{\text {a }}$ Kim Vanmeensel ${ }^{\text {a }}$ \\ ${ }^{a}$ KU Leuven, Department of Materials Engineering, Kasteelpark Arenberg 44, B-3001 Heverlee, \\ Belgium \\ ${ }^{\mathrm{b}}$ KU Leuven, Department of Mechanical Engineering, \& Member of Flanders Make, Celestijnenlaan \\ 300, B-3001 Heverlee, Belgium \\ ${ }^{c}$ KTH Royal Institute of Technology, Department of Production Engineering, Brinellvägen 68, SE- \\ 10044 Stockholm, Sweden
}

*Corresponding author: E-mail address: suraj.jadhav@ kuleuven.be

Keywords: Powder surface modification; Modified CuCr1 powder; Laser powder bed fusion; Selective laser melting; Copper reflectivity

\begin{abstract}
Owing to the high optical reflectivity of copper, silver, and gold in the infrared region, high laser power is required for laser-based additive manufacturing (L-AM). This increases the risk of damaging the laser optics due to sustained back-reflections and renders L-AM of reflective metals an unsustainable technology. To tackle this issue, a novel, industrially upscalable powder surface modification method is proposed and validated using a $\mathrm{CuCr} 1$ alloy. The surface of $\mathrm{CuCr} 1$ powder is modified by the outward diffusion of chromium in a nitrogen atmosphere, forming a rim around the powder particles. This doubled the optical absorption of the powder. Consequently, a mere $20 \%$ of the laser energy is required to process the surface-modified powder by laser powder bed fusion compared to the virgin $\mathrm{CuCr} 1$ powder. The fabricated parts demonstrate a very high thermal conductivity of 370 $\pm 15 \mathrm{~W} /(\mathrm{m} \cdot \mathrm{K})$ and tensile strength of $439 \pm 19 \mathrm{MPa}$, after applying a suitable post-heat treatment.
\end{abstract}




\section{Introduction}

Laser powder bed fusion (LPBF), also known as selective laser melting (SLM), is an additive manufacturing (AM) process that uses a high-density laser to selectively melt and fuse powder layers, forming 3D parts [1]. Due to its additive nature, customized and complex-shaped 3D parts with improved surface area to volume ratio can be fabricated with a low material wastage. The parts with high surface area to volume ratio could substantially improve the efficiency of heat transfer devices $[2,3]$. However, the reliable fabrication of dense parts from highly conductive copper alloy powders, using a fiber laser, is still challenging [4,5]. On the one hand, this is due to the high optical reflectivity of copper for infrared radiation, which multiplies the required energy to produce dense parts, even above the capacity of the commonly used fiber lasers. Moreover, the high copper back-reflections can damage the components of the optical system of the LPBF machine [6]. On the other hand, the high intrinsic thermal conductivity of copper rapidly dissipates the absorbed heat and demands more energy for successful LPBF production.

Considering the ability of the LPBF process to fabricate geometrically complex-shaped parts, there is a tremendous potential for improving the heat transfer efficiency of thermal management objects. This potential will further be multiplied; if highly conductive copper and copper alloy powders could be processed by LPBF [7]. Within such developments, multiple attempts have been undertaken to fabricate dense copper parts using commercially available fiber lasers with output power values up to $400 \mathrm{~W}$. However, the available laser power was not sufficient to melt the powder particles resulting in low-density copper parts with lack-of-fusion defects [4,8-10]. Accordingly, few researchers utilized a high-power $1 \mathrm{~kW}$ laser with a focused beam-diameter below $100 \mu \mathrm{m}$ [6,11-13]. The use of high laser power of $600-800 \mathrm{~W}$, in combination with a low scanning speed $(200-400 \mathrm{~mm} / \mathrm{s})$, resulted in the fabrication of nearly dense (96-99\%) copper parts $[6,12,14]$. However, the sustained copper backreflections damaged the optical mirrors of the LPBF machine [6]. Therefore, the authors discourage the use of high-power fiber laser for processing such a highly reflective material powder and suggest to use green or blue lasers, for which copper exhibits higher optical absorptivity due to the interband electronic transition mechanism [15]. Recently, green [16,17] and blue [18] lasers have been used in laser metal deposition (LMD) [19,20], and laser welding [21] processes and attempts are being made to process pure copper via LPBF. However, neither mechanical nor electrical or thermal properties of such parts have yet been reported. Although the high optical absorption of copper at the wavelength of green or blue laser encourages their incorporation in LPBF machines, this technology is costly and still under development [16-18]. Moreover, the AM industry prefers to use the existing LPBF machines equipped with traditional fiber lasers, radiating light with a wavelength of around $1080 \mathrm{~nm}$, which allows the processing of a wide variety of metallic alloys, such as Ti-6Al-4V, AlSi10Mg, stainless steel.

Since upgrading the LPBF machine with a green or blue laser to process pure copper is not always economically or technologically feasible, some authors have evaluated the use of pre-alloyed, gas-atomized copper powder with a small amount $(<1 \mathrm{wt} . \%)$ of alloying elements, such as chromium and zirconium [22-25]. However, this is still not a sustainable approach, since the alloying element is distributed uniformly within the copper powder particles, and thus, the pre-alloyed copper powders exhibit similar laser reflectivity values as pure copper. Hence, comparable LPBF processing behavior is expected [26]. Accordingly, rather dense copper parts could only be obtained within a narrow LPBF processing window, provided that a combination of fine particles (D50: 20 $\mu \mathrm{m}$ ), thin powder layers ( $\leq$ $20 \mu \mathrm{m})$, low laser scan speeds $(200-400 \mathrm{~mm} / \mathrm{s})$, and high laser power values $(>350 \mathrm{~W})$ are employed [8,23-25]. Moreover, the fabrication of copper parts at a low laser scan speed (low productivity) requires a high laser scan time per layer. The high laser scan time per layer, along with the high laser power, increases the probability of copper back-reflections and potentially contributes to the worsening of the thermal lensing effect, which is induced by the temperature gradient within the optical elements 
(fibers and lenses) [27]. The thermal lensing effect ensued within lenses causes a shift of the laser focal plane away from the powder bed during the LPBF process. Thus, an altered LPBF behavior and concomitant variation in part density and performance could be obtained [27]. As an alternative approach, surface modification of copper powder by the addition of carbon nanoparticles for improving the powder optical absorption has been evaluated [14,25]. The use of carbon-mixed copper powder exhibiting a high optical absorption of 56-67\% could have assisted in the formation of a stable melt pool at the start of each melt track. However, the melt pool stability could not be maintained along the complete melt track due to the segregation of carbon nanoparticles along the melt pool borders. Consequently, no significant difference in the LPBF behavior, between the virgin $\mathrm{CuCr} 0.3$ and carbonmixed $\mathrm{CuCr} 0.3$ powders, was observed [25]. Hence, the current state-of-the-art technology cannot offer a reliable (safe, consistent, flexible, and low energy consumption) fabrication of dense, highlyconductive copper parts. Therefore, there is a need to develop fiber laser-friendly copper alloy powders for the reliable LPBF production of copper components with high thermal and electrical conductivity.

Accordingly, to print highly conductive and high strength copper alloys, this research proposes a novel and industrially upscalable powder surface modification method, comprising a surface-modified $\mathrm{CuCr} 1$ powder with a very high optical absorption. The surface modification relies on the outward diffusion of chromium towards the powder surface, driven by the presence of a surrounding nitrogen atmosphere at elevated temperatures. Initially, the powder surface treatment is explained and optimized. Subsequently, the resulting powder properties are compared with the virgin $\mathrm{CuCr} 1$ powder, and the LPBF processing behaviors of both virgin and surface-modified $\mathrm{CuCr} 1$ alloy powders are compared. Finally, the surface-modified $\mathrm{CuCr} 1$ powder is used to fabricate high conductivity industrial parts with various geometries and complexities to validate the upscalability of this approach, and the thermal, electrical, and tensile properties are reported for the as-built and the optimum solution annealing and age hardening $(\mathrm{SA}+\mathrm{AH})$ conditions.

\section{Materials and Methods}

\subsection{Virgin Powder}

Pre-alloyed, argon atomized $\mathrm{CuCr} 1$ powder with D50 of $38.8 \mu \mathrm{m}$, was procured from Nanoval GmbH \& Co. KG, Germany. The powder particle size distribution (PSD) was measured on unfused powders after LPBF experiments, using the LS 13320 laser diffraction particle size analyzer by Beckman Coulter Inc., and the PSD's of both virgin and surface-modified CuCr1 powders are plotted in Figure 1. The virgin $\mathrm{CuCr} 1$ powder particles were mainly spherical and exhibited a smooth outer surface. The virgin $\mathrm{CuCr} 1$ powder contained 0.89 wt. $\% \mathrm{Cr}, 0.0017 \mathrm{wt} . \% \mathrm{O}$, and 0.0008 wt. $\% \mathrm{~N}$ with a balance amount of copper. The chromium content was measured using inductively coupled plasma optical emission spectroscopy (ICP-OES), Varian $720 \mathrm{ES}$, while the oxygen and nitrogen contents were measured using the inert gas fusion techniques of Leco. 


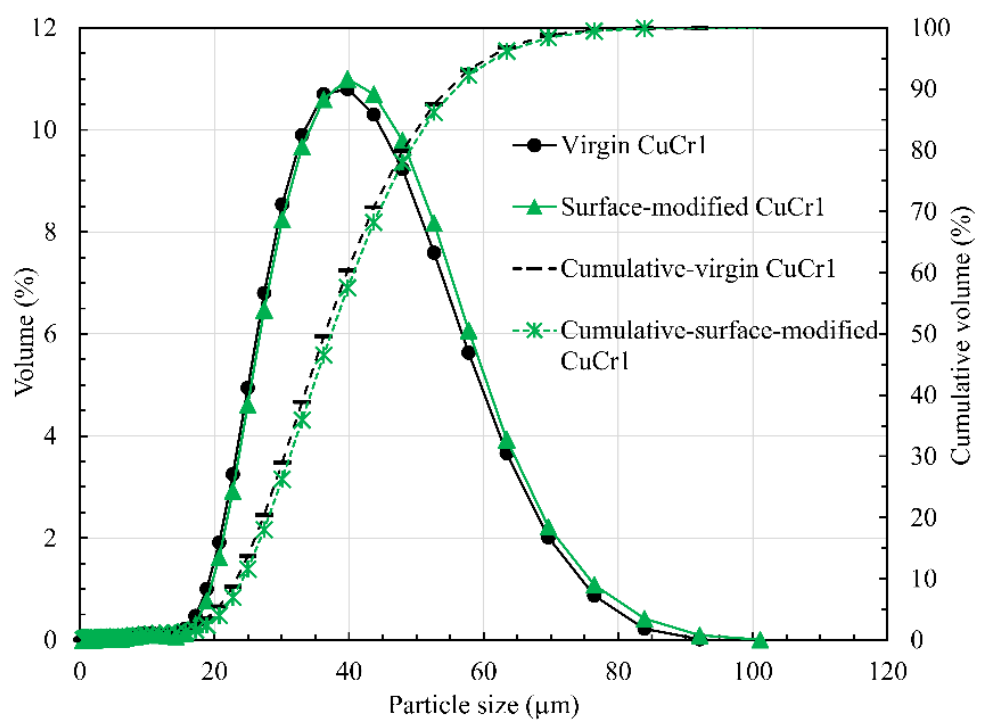

Figure 1: Particle size distribution (PSD) of the virgin and surface-modified $\mathrm{CuCr} 1$ powders, measured on unfused powders after LPBF experiments. D50 values of 39.9 $\mu \mathrm{m}$ and $41 \mu \mathrm{m}$ are recorded for the virgin and surface-modified $\mathrm{CuCr} 1$ powders, respectively.

\subsection{Surface Modification Method, Process Optimization, and the Surface-modified Powder}

The virgin $\mathrm{CuCr} 1$ powder, kept in an alumina crucible, was heat-treated in a tube furnace under flowing nitrogen $(99.99 \%)$ atmosphere. Initially, the powder was heat-treated at various temperatures between $400-900^{\circ} \mathrm{C}$ for $1 \mathrm{~h}$, followed by furnace cooling. During the heat-treatment (HT), the heating and cooling rates were fixed at $5{ }^{\circ} \mathrm{C} / \mathrm{min}$. Subsequently, the optical absorption of the virgin and surfacemodified $\mathrm{CuCr} 1$ powders was measured using a lambda 950 spectrophotometer of PerkinElmer, and the nitrogen content was determined using the Leco test. Heat treating the $\mathrm{CuCr} 1$ powder at $750^{\circ} \mathrm{C}$ for 1h, in nitrogen atmosphere proved to be optimal because: (i) a saturation in the optical absorption was observed above $750^{\circ} \mathrm{C}$, and (ii) excessive sintering of individual powder particles took place at elevated temperatures between $800-900^{\circ} \mathrm{C}$. After defining the optimum heat treatment condition for the $\mathrm{CuCr} 1$ powder surface-modification, multiple batches $(1.5 \mathrm{~kg} / \mathrm{batch})$ of the surface-modified $\mathrm{CuCr} 1$ powder were produced. The surface-modified $\mathrm{CuCr} 1$ powder was dry-mixed using a multidirectional Turbula mixer and sieved using a sieve with a pore size of $63 \mu \mathrm{m}$. To measure the thickness of the surfacemodified layer, composed of metallic chromium and chromium-nitrides, the particles were first coated with a $1 \mu \mathrm{m}$ thick Pt layer. Subsequently, the powder particle was cut using a focused Ga ion beam coupled to a scanning electron microscope (FIB-SEM, Dual-beam, Nova 600 Nanolab, FEI), and the thickness was measured based on the EDS elemental map of the surface-modified layer. Within the current article, the $\mathrm{CuCr} 1$ powder before heat treatment is referred to as the virgin powder, while after heat treatment $\left(750^{\circ} \mathrm{C}, 1 \mathrm{~h}, \mathrm{~N}_{2}\right)$, it is labeled as the surface-modified powder.

\subsection{Characterization of the Virgin and Surface-modified CuCr1 Powders}

The surface of the virgin and surface-modified $\mathrm{CuCr} 1$ powders was visualized using a scanning electron microscope (SEM) XL30, FEG, Philips, The Netherlands. Elemental mapping of chromium and nitrogen on the powder particle surface was performed using the energy-dispersive X-ray spectroscopy (EDS) technique. The phase identification for both powders was carried out using the Xray diffraction (XRD) analysis. The XRD spectra were collected within the $30-95^{\circ} 2 \theta$ range, at a step size of $0.02^{\circ}$ and time per step of 1s. The diffraction patterns were recorded on a Bruker D2 machine equipped with a $\mathrm{Cu} \mathrm{K} \alpha \mathrm{X}$-ray source. The dynamic angle of repose (dAoR) test was performed on both virgin and surface-modified $\mathrm{CuCr} 1$ powders. The values for average and avalanche angle of repose are reported. Lower average and avalanche angle of repose indicate better powder flowability [14]. To investigate the effect of the surface modification technique on the oxidation behavior of $\mathrm{CuCr} 1$ powder, 
the virgin and surface-modified $\mathrm{CuCr} 1$ powders were stored in polyethylene bottles at room temperature without any atmospheric control. The oxygen content for both powders was measured periodically over a span of one year using the inert gas fusion technique of Leco.

\subsection{LPBF Processing Behavior and Part Fabrication}

At first, standard triangle language (STL) files for cube-shaped parts were prepared using the Magics software, Materialise, Belgium. The parts were hatched by applying a $90^{\circ}$ scan rotation angle between the successive layers and a zigzag (bi-directional) scan strategy within each layer. The fabrication of all parts was carried out in an in-house developed LPBF machine equipped with a continuous single-mode, $1 \mathrm{~kW}$ fiber laser, emitting light with a wavelength of $1080 \mathrm{~nm}$, and a beam diameter of $0.04 \mathrm{~mm}, 1 / \mathrm{e}^{2}$ value [28-30]. All parts were fabricated on a pure copper baseplate without preheating under a protective argon atmosphere maintaining the oxygen content below $50 \mathrm{ppm}$ throughout the built. The parameter optimization was carried out within the laser power $(P)$ range of $200-500 \mathrm{~W}$, laser scan speed $(v)$ range of $200-1400 \mathrm{~mm} / \mathrm{s}$, hatch spacing $(h)$ of 0.09 , or $0.105 \mathrm{~mm}$, and at a fixed layer thickness $(t)$ of $0.03 \mathrm{~mm}$. The layers were deposited using a soft coater to make sure that the largest powder particles were also deposited. The volumetric laser energy density $(E)$ was calculated using equation 1 .

$$
E=\frac{P}{v \times h \times t}
$$

Where,

$$
\begin{aligned}
& E: \text { Volumetric laser energy density }\left(\mathrm{J} / \mathrm{mm}^{3}\right) \\
& P: \text { Laser powder }(\mathrm{W}) \\
& v: \text { Laser scan speed }(\mathrm{mm} / \mathrm{s}) \\
& h: \text { Hatch spacing }(\mathrm{mm}) \\
& t: \text { Layer thickness }(\mathrm{mm})
\end{aligned}
$$

Cube-shaped parts with dimensions of $(10 \times 10 \times 7) \mathrm{mm}^{3}$ were fabricated using different laser scan settings. The part densities were measured using the Archimedes method after removal of the parts from the baseplate. The relative part density values were reported after dividing the Archimedes density values by the theoretical density $(8.903 \mathrm{~g} / \mathrm{cc}$ for the virgin $\mathrm{CuCr} 1$ powder, or $8.912 \mathrm{~g} / \mathrm{cc}$ for the surfacemodified $\mathrm{CuCr} 1$ powder). The theoretical density values were determined by a helium pycnometry technique using a Multipycnometer ${ }^{\mathrm{TM}}$ of Quantachrome Instruments. The optimized LPBF parameter set $(P$ of $500 \mathrm{~W}, v$ of $800 \mathrm{~mm} / \mathrm{s}, h$ of $0.09 \mathrm{~mm}$, and $t$ of $0.03 \mathrm{~mm}$ ), resulting in the fabrication of dense parts made of the surface-modified $\mathrm{CuCr} 1$ powder, was used to fabricate multiple industrial parts with different dimensions and geometrical complexities. Tensile tests were performed on flat dog-bone shaped samples, according to the ISO 6892 standard, at a constant cross-head speed of $0.4 \mathrm{~mm} / \mathrm{s}$ using an Instron 4467 machine and the strains were recorded using an extensometer. The tensile tests were performed on the as-built as well as the optimized SA+AH (solution annealing (SA) at $1050^{\circ} \mathrm{C}, 1 \mathrm{~h}$, water quench, and age hardening $(\mathrm{AH})$ at $450^{\circ} \mathrm{C}, 7 \mathrm{~h}$, water quench) samples. The optimum $\mathrm{SA}+\mathrm{AH}$ condition was chosen, which offered the highest value for the product of electrical conductivity and hardness. The electrical conductivity was measured at room temperature by a four-point contact method using Resistomat ${ }^{\circledR}$ model $2301-\mathrm{V} 001$ of Burster on samples with dimensions of $(60 \times 5 \times 2) \mathrm{mm}^{3}$. Thermal diffusivity of the built parts $(10 \times 10 \times 2) \mathrm{mm}^{3}$, was measured using a micro-laser flash technique, LFA 457, Netzsch instruments at room temperature, and thermal conductivities were calculated and reported in $\mathrm{W} /(\mathrm{m} \cdot \mathrm{K})$. Microstructural analysis of samples was performed on a polished 
cross-sectional surface after etching with a chemical solution comprised of $2.5 \mathrm{~mL} \mathrm{HCl}, 3.5 \mathrm{~g} \mathrm{FeCl}$, and $75 \mathrm{~mL} \mathrm{C}_{2} \mathrm{H}_{5} \mathrm{OH}$, for both as-built $(\mathrm{AB})$ and $\mathrm{SA}+\mathrm{AH}$ conditions.

\section{Results}

\subsection{Optimization of the Powder Surface Modification Method}

\subsubsection{Evolution of Powder Optical Absorption and Nitrogen Content with Heat Treatment Temperature and Powder Surface Morphology}

The virgin $\mathrm{CuCr} 1$ powder was heat-treated at various temperatures for one hour in the nitrogen atmosphere, and the optical absorption and nitrogen content were measured for all powders. Figures 2(a) \& (b) show the evolution of the optical absorption and nitrogen content of the $\mathrm{CuCr} 1$ powders heattreated at various temperatures. As seen, the optical absorption of the virgin $\mathrm{CuCr} 1$ powder (34\%) at $1080 \mathrm{~nm}$ wavelength is slightly higher than that of the pure copper powder (26\%). Up to a heat treatment temperature of $500^{\circ} \mathrm{C}$, the optical absorption values of $\mathrm{CuCr} 1$ powders remain unaltered at the fiber laser wavelength. Note that minor variations in the measurements could occur due to the difference in powder packing density and powder surface condition. However, when heat treatment temperatures of $600^{\circ} \mathrm{C}$ or higher were employed, a significant increase in the optical absorption is observed at the fiber laser wavelength of $1080 \mathrm{~nm}$. The optical absorption saturates at $\sim 70 \%$ when the heat treatment temperature was increased to $750^{\circ} \mathrm{C}$ and above. On the other hand, the nitrogen content in the $\mathrm{CuCr} 1$ powder increases with increasing heat treatment temperature, similar to the optical absorption. Yet, no saturation at higher temperatures of $750-900^{\circ} \mathrm{C}$ is observed, as shown in Figure 2(b). Figure 2(c) shows a high magnification secondary electron (SE) image of the surface of a virgin $\mathrm{CuCr1}$ powder particle. The powder particle surface is smooth without any surface abnormalities. However, after heating the $\mathrm{CuCr} 1$ powder at $750^{\circ} \mathrm{C}$ for $1 \mathrm{~h}$ in the nitrogen atmosphere, nanometer-size precipitates appear at the powder surface, as indicated using white arrows in Figure 2(d). EDS mapping of this surface shows that these precipitates are composed of chromium and nitrogen, as shown in Figures 2(e \& f). The size and density distribution of these precipitates are higher near the grain boundary (also refer to Supplementary Figure 1). 

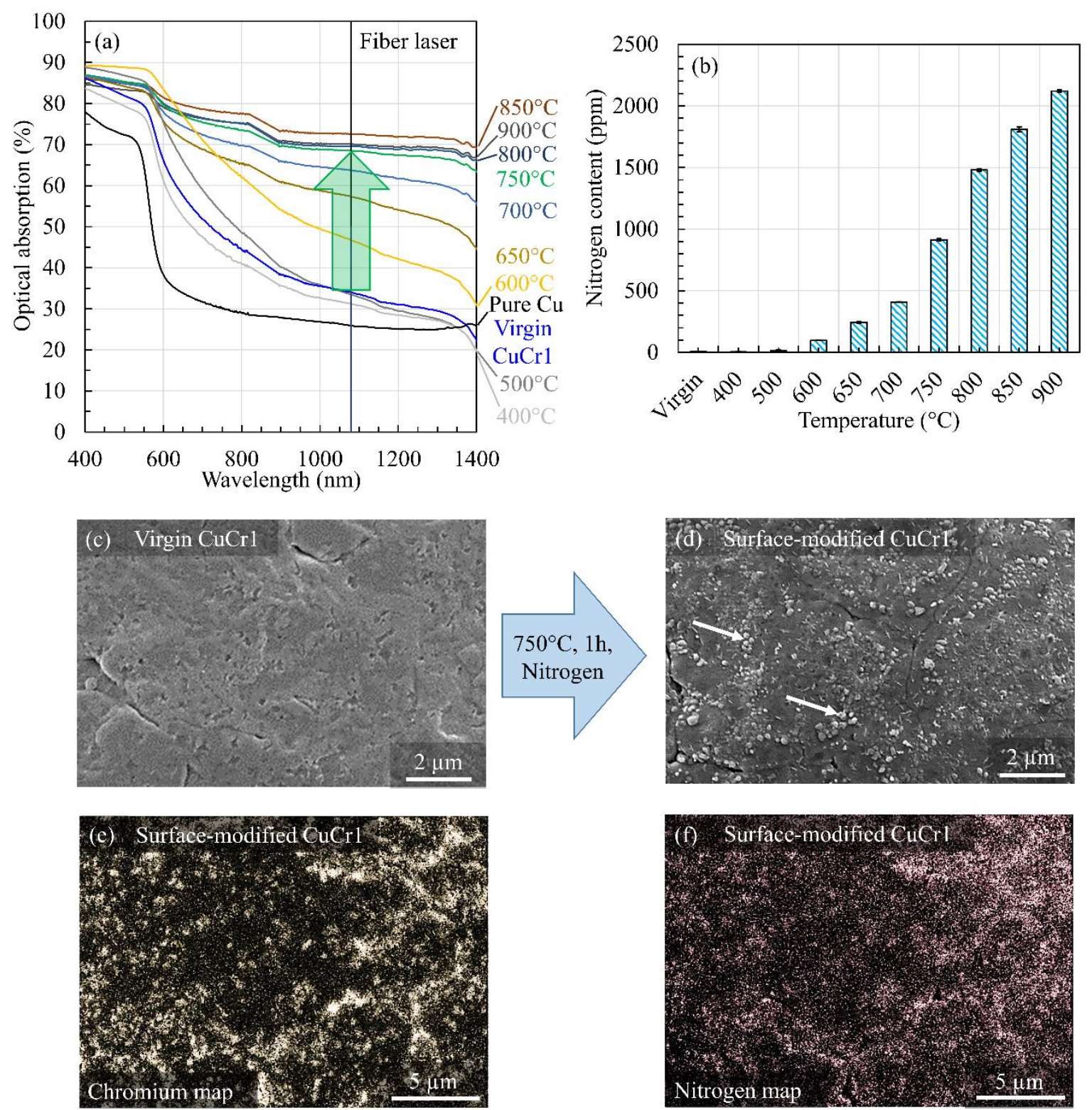

Figure 2: (a) Evolution of the optical absorption of $\mathrm{CuCr} 1$ powder at different wavelengths for various heat treatment temperatures for one hour in the nitrogen atmosphere. (b) Nitrogen content of the $\mathrm{CuCr} 1$ powders as a function of heat treatment temperature. (c) \& (d) SEM images of the surface of a virgin and surface-modified $\left(750^{\circ} \mathrm{C}, 1 \mathrm{~h}, \mathrm{~N}_{2}\right) \mathrm{CuCr} 1$ powder particle, respectively. The white arrows indicate the nanometer-sized precipitate formation. (e) \& (f) EDS maps for chromium and nitrogen at the surface of the surface-modified $\mathrm{CuCr} 1$ powder particle, respectively. The bright color, in the EDS maps, represents regions that are rich in chromium, and/or nitrogen, whereas the dark-colored regions are depleted of these elements.

\subsubsection{X-ray Diffraction and EDS Analysis of the Virgin and Surface-modified CuCr1 Powders}

Figure 3(a) shows the X-ray diffraction (XRD) spectra recorded for the virgin and surfacemodified $\mathrm{CuCr} 1$ powders. All spectra show dominant copper peaks indexed with the corresponding miller indices. Figures 3 (b) \& (c) show a closer view within the $37-38^{\circ} 2 \theta$ range, presented for the chromium nitride (110) peak, and $43.5-45^{\circ}$ displayed for the metallic chromium (101) peak. As seen, 
the XRD spectra for the virgin powder and powders heat-treated up to $500^{\circ} \mathrm{C}$, do not show any presence of chromium and chromium nitride phases. However, above $600^{\circ} \mathrm{C}$ and up to $750^{\circ} \mathrm{C}$, a small yet intensifying chromium peak appear, as indicated in Figure 3(c). This suggests that the chromium, which was originally homogeneously distributed within the powder particles, is diffusing outwards, and the powder surface is getting enriched in metallic chromium. However, at $800^{\circ} \mathrm{C}$ and higher temperatures, the chromium peak gradually diminishes, and instead, the chromium nitride peak appears and intensifies. This trend within XRD spectra could be associated with the reaction of chromium and nitrogen forming chromium nitrides $\left(\mathrm{Cr}_{2} \mathrm{~N}, \mathrm{CrN}\right)$. Although the chromium nitride peak is intensified above $750^{\circ} \mathrm{C}$, a small metallic chromium peak remains. This demonstrates that the surface-modified layer of $\mathrm{CuCr} 1$ is usually composed of a mixture of metallic chromium and chromium nitrides. The optimum heat treatment temperature of $750^{\circ} \mathrm{C}$ was chosen to attain a high optical absorption of $\sim 70 \%$ in combination with a minimum amount of sintering of the powder particles.

Figures 3(d) \& (e) show a SEM image and chromium EDS map for the cross-section of virgin $\mathrm{CuCr} 1$ powder particles, in comparison to Figures $3(\mathrm{f}) \&(\mathrm{~g})$ which display the corresponding images for the surface-modified $\mathrm{CuCr} 1$ powder particles $\left(750^{\circ} \mathrm{C}, 1 \mathrm{~h}, \mathrm{~N}_{2}\right)$. The EDS map of the virgin $\mathrm{CuCr} 1$ powder particles shows a uniform distribution of chromium (1.8 at.\%) within the powder particles. However, after the heat treatment at $750^{\circ} \mathrm{C}$, preferential segregation of chromium (45.3 at.\%), forming a rim around the powder particles is observed. Moreover, similar segregation of nitrogen (25.9 at.\%) is also observed, forming a nitrogen-rich shell around the heat-treated powder particles, as shown in the inset of Figure 3(f). The EDS maps of chromium and nitrogen validate the XRD results, which indicated that the surface-modified layer is composed of a mixture of chromium and chromium-nitrides (also refer to Supplementary Figure 1). 

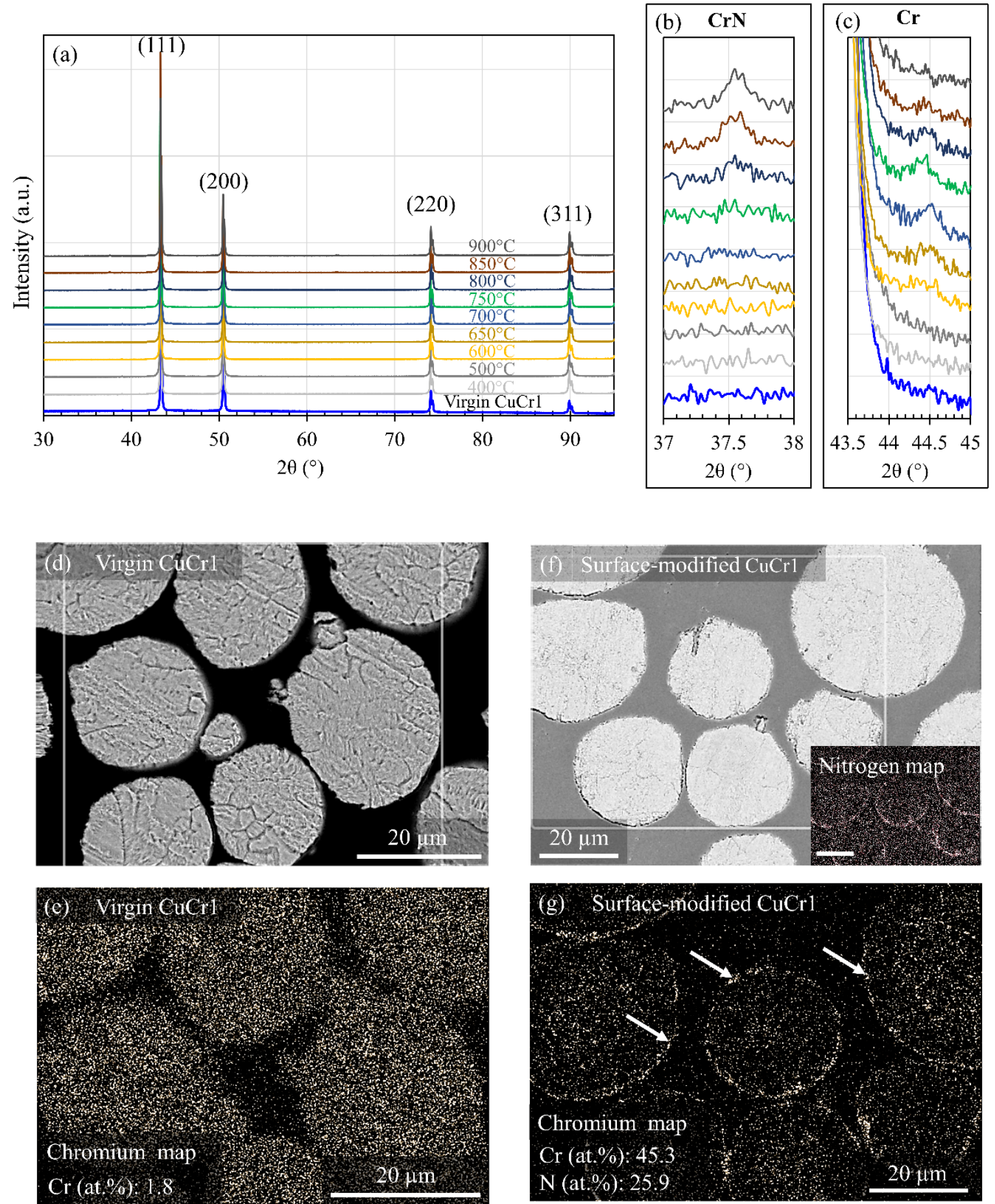

Figure 3: (a) X-ray diffraction spectra for the virgin and surface-modified $\mathrm{CuCr} 1$ powders. The $\mathrm{CuCr} 1$ powder was heat-treated at various temperatures between $400-900^{\circ} \mathrm{C}$, for $1 \mathrm{~h}$, in a nitrogen

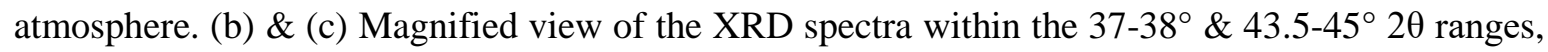
represented for the presence of chromium nitride and metallic chromium phases, respectively. (d) \& (e) SEM image and EDS chromium map of the cross-section of the virgin $\mathrm{CuCr} 1$ powder particles. The EDS map shows a uniform distribution of chromium (1.8 at.\%) throughout the powder particle cross-section. (f) \& (g) SEM image and EDS chromium map of the surface-modified $\mathrm{CuCr} 1$ powder particles. The inset of figure (f) shows a nitrogen distribution map. After the heat treatment at $750^{\circ} \mathrm{C}$, for $1 \mathrm{~h}$, in the nitrogen atmosphere, a rim composed of chromium (45.3 at.\%) and nitrogen (25.9 at.\%) indicated using white arrows surrounding the copper powder particle is observed. The bright color, 
in the EDS maps, represents regions that are rich in chromium, and/or nitrogen, whereas the darkcolored regions are depleted of these elements.

\subsection{FIB Section and EDS Mapping of a Surface-modified Powder Particle}

Figure 4(a) shows the cross-section of a surface-modified $\left(750^{\circ} \mathrm{C}, 1 \mathrm{~h}, \mathrm{~N}_{2}\right) \mathrm{CuCr} 1$ powder particle (the inset shows the powder particle before cutting). On the cross-sectional surface, a darkcolored, continuous layer surrounding the particle surface can be observed, indicated by yellow arrows, whereas in the core, the same dark phase is mainly segregated along the grain boundaries, as indicated by white arrows. This phase can be better identified based on Figures 4 (b) \& (c), demonstrating the EDS maps for chromium and nitrogen, respectively. In Figure 4(b), three different zones, labeled as A, $\mathrm{B}$, and $\mathrm{C}$, can be identified throughout the cross-section of the powder particle. Zone A, situated in the powder core, demonstrates the segregated chromium along the grain boundaries. Zone B, located between the powder surface and the core, is depleted in chromium, and therefore, it can be termed as the chromium-free zone. It could be stated that this zone is formed by the outward diffusion of chromium towards the powder surface due to the high chemical affinity between chromium and nitrogen at $750^{\circ} \mathrm{C}$. Zone $\mathrm{C}$ is the surface layer generated by the combination of the outward diffusion of chromium and the reaction of chromium and nitrogen forming chromium nitrides. A magnified view of the particle cross-section, in Figure 5, shows that zone $\mathrm{C}$ is, in fact, the surface-modified layer, which includes both metallic chromium and chromium nitride layers. Based on the EDS color map shown in Figure 5(b), three different (green, orange-brown, and red) colored layers within the surface-modified layer are evident. These colors demonstrate dissimilar chemical compositions. The green-colored layer present at the outermost side of the surface-modified layer is composed of nearly equal amounts of nitrogen and chromium; hence, it could be identified as the $\mathrm{CrN}$ phase. The middle, orange-browncolored layer contains a lower amount of nitrogen compared to the outermost green layer; thus, it could be denoted as a $\mathrm{Cr}_{2} \mathrm{~N}$ phase. Finally, the innermost, red-colored layer is rich in chromium; therefore, it could be labeled as the metallic chromium phase. According to these color shades, the total thickness of the surface-modified layer (including both metallic chromium and chromium nitride) is $459 \pm 50 \mathrm{~nm}$, while the thickness of the metallic chromium layer alone is $178 \pm 17 \mathrm{~nm}$. Therefore, the thickness of the chromium nitride layer $\left(\mathrm{Cr}_{2} \mathrm{~N}+\mathrm{CrN}\right)$ can be estimated to be $\sim 280 \mathrm{~nm}$, and it is plausibly present at the outermost side within the surface-modified layer.
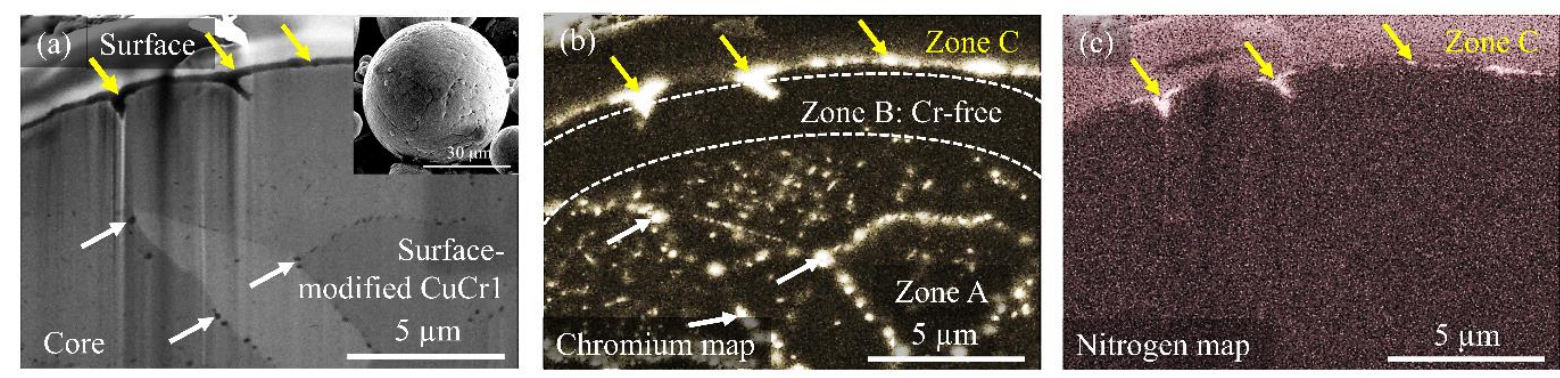

Figure 4: (a) SEM image of the cross-section of a powder particle heat-treated at $750^{\circ} \mathrm{C}$, for $1 \mathrm{~h}$, in a nitrogen atmosphere. The inset shows the powder particle before cutting. (b) \& (c) EDS maps of chromium and nitrogen within the powder cross-section, respectively. The bright color, in the EDS maps, represents regions that are rich in chromium, and/or nitrogen, whereas the dark-colored regions are depleted of these elements. 

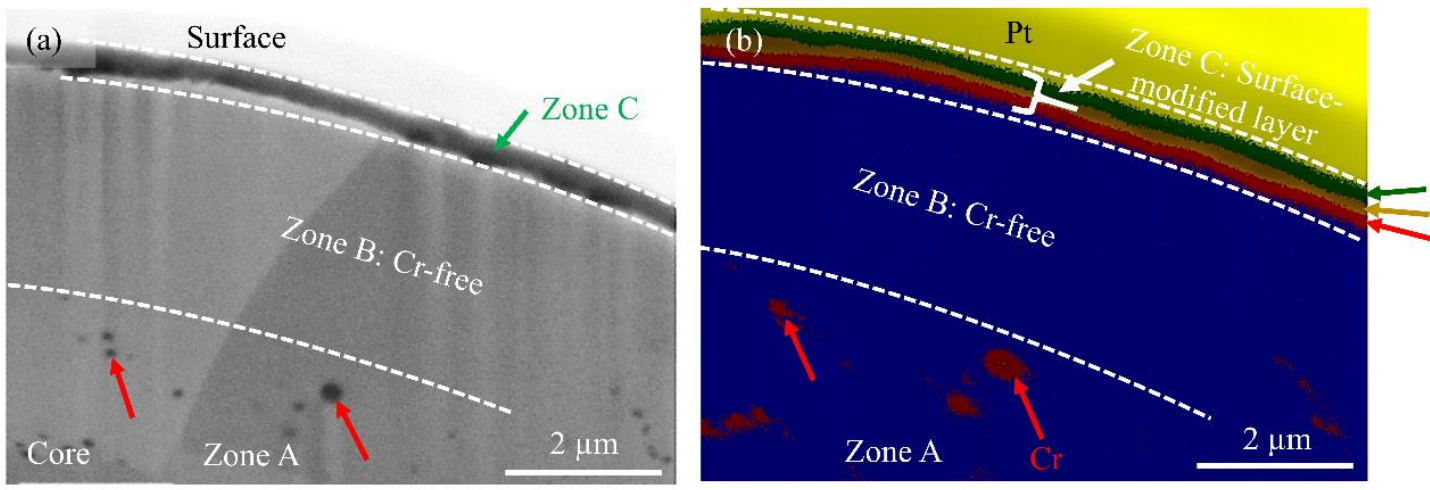

\begin{tabular}{lll}
\hline Layer color & Composition (at.\%) & Possible phases \\
\hline Yellow & $\mathrm{Pt}$ & $\mathbf{P t}$ \\
Grecn & $\mathrm{Cr}: 14.9, \mathrm{~N}: 17.6$ & $\mathrm{CrN},\left(\mathrm{Cr}_{2} \mathrm{~N}, \mathrm{Cr}\right)$ \\
Orange-Brown & $\mathrm{Cr}: 16.9, \mathrm{~N}: 10.5$ & $\mathrm{Cr}_{2} \mathrm{~N},(\mathrm{Cr}, \mathrm{CrN})$ \\
Red & $\mathrm{Cr}: 4.2, \mathrm{~N}: 1.2$ & $\mathrm{Metallic} \mathrm{Cr},\left(\mathrm{Cr}{ }_{2} \mathrm{~N}, \mathrm{CrN}\right)$ \\
Blue & $\mathrm{Cu}$ & $\mathrm{Cu}$ \\
\hline
\end{tabular}

Figure 5: (a) Magnified view of the surface-modified $\mathrm{CuCr} 1$ powder particle cross-section showing zone A, B, and C. (b) Composition-based color maps obtained after EDS mapping of the powder particle cross-section. In total, five different colors (yellow, green, orange-brown, red, and blue) representing dissimilar chemical compositions can be identified. The table outlines different colors along with their respective chemical compositions and possible phases, as denoted in (b) by colored arrows. It is important to note that the phases indicated in brackets may exist in small amounts along with the main phase shown in bold letters for the respective color. It can be seen that the outermost, green-colored layer of the surface-modified layer is enriched with nitrogen, while the innermost, redcolored layer is dominated by chromium. The yellow-colored layer, composed of platinum, was applied on the powder particle to protect the surface-modified layer during FIB cutting.

\subsection{Powder Flowability and Oxygen Pickup}

Figure 6(a) shows that the surface-modified powder exhibits an overall lower average and avalanche angle of repose compared to the virgin $\mathrm{CuCr} 1$ powder. This indicates that the powder flowability is improved upon the heat treatment of the $\mathrm{CuCr} 1$ alloy powder in the nitrogen atmosphere. Figure 6(b) shows the evolution of oxygen content of the virgin and surface-modified $\mathrm{CuCr} 1$ powders during their storage in a polyethylene bottle at room temperature for twelve months, without controlling the atmosphere. As seen, the oxygen content of the virgin $\mathrm{CuCr1}$ powder increases up to $2200 \mathrm{ppm}$ within twelve months. However, no significant increase in the oxygen content occurs for the surfacemodified $\mathrm{CuCr} 1$ powder. Hence, the surface-modified $\mathrm{CuCr} 1$ powder demonstrates improved powder storage life by minimizing its natural oxidation. Lower oxygen content in the initial $\mathrm{CuCr}$ alloy powder is beneficial for tailoring the mechanical properties of the fabricated parts by post-heat-treatments [25]. 

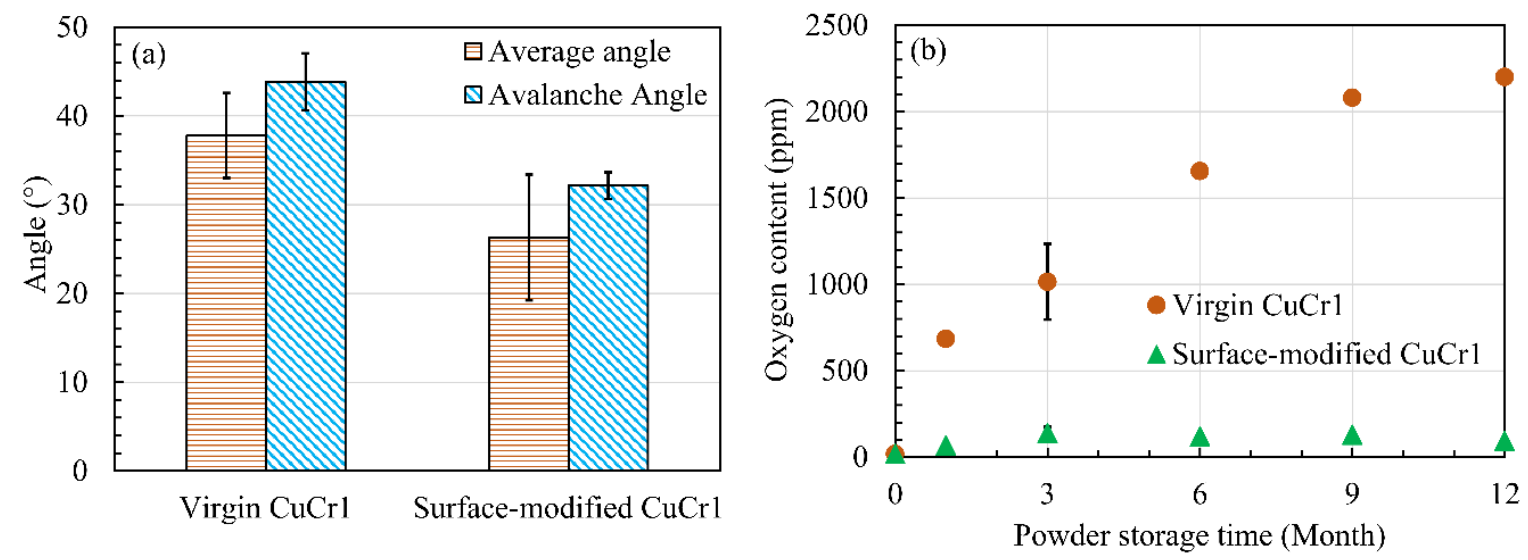

Figure 6: (a) The average and avalanche angles of the virgin and surface-modified $\mathrm{CuCr} 1$ powders during the dynamic angle of repose test. (b) The oxygen pickup of both powders after twelve months of unprotected storage at room temperature. Note that the standard deviations for the oxygen content measurements are too small to be visible, except for the month three measurements.

\subsection{LPBF Process Optimization and Top and Cross-section Surface Observation}

Figures 7 (a) \& (b) display the relative density of the parts as a function of the applied volumetric laser energy density $(E)$, at different laser powers $(P)$ levels, when both virgin and surface-modified $\mathrm{CuCr} 1$ powders were used, respectively. The laser scan speeds $(v)$ are denoted for the parts processed using a fixed laser power of $500 \mathrm{~W}$ and hatch spacing $(h)$ of $0.09 \mathrm{~mm}$. In general, for the same laser power, the virgin $\mathrm{CuCr} 1$ powder requires much higher volumetric laser energy density for densification compared to the surface-modified $\mathrm{CuCr} 1$ powder. For example, at a laser power of $500 \mathrm{~W}$, to achieve a $98.6 \%$ dense part from the virgin CuCr1 powder, a volumetric laser energy density of $926 \mathrm{~J} / \mathrm{mm}^{3}$ is required, while a similar part density could be obtained at a much lower volumetric laser energy density of $185 \mathrm{~J} / \mathrm{mm}^{3}$ when using the surface-modified $\mathrm{CuCr} 1$ powder. Figure 7(a) shows that a high-density part $(\geq 98 \%)$ made of virgin $\mathrm{CuCr} 1$ powder can only be obtained by applying a high laser power of $500 \mathrm{~W}$ coupled with a low laser scan speed of 200 or $300 \mathrm{~mm} / \mathrm{s}$. On the contrary, Figure 7(b) demonstrates that the high-density part made of surface-modified $\mathrm{CuCr} 1$ powder can be obtained for a wide range of laser scan speeds $(400-1400 \mathrm{~mm} / \mathrm{s})$, provided that a laser power of 450 or $500 \mathrm{~W}$ is used. This indicates that the use of surface-modified $\mathrm{CuCr} 1$ powder in LPBF could improve the process flexibility and productivity while minimizing the risk of damaging the optical components of the machine. Note that, for both powders, a laser power below $400 \mathrm{~W}$ did not allow the production of dense parts for the selected range of PSD and LPBF settings. This indicates that laser power values lower than $400 \mathrm{~W}$, fall below the minimum laser power required for the complete fusion of the powder particles [31]. Consequently, unlike the other laser processable alloys, the volumetric laser energy density alone cannot explain the densification behavior of the highly conductive $\mathrm{CuCr} 1$ alloy powders. The higher value of the minimum laser power required for the processing $\mathrm{CuCr} 1$ alloy is attributed to the high thermal conductivity and the high optical reflectivity, which hinder the complete fusion of the powder particles by rapidly dissipating the limited amount of absorbed heat during the LPBF process [32].

Figures 7(c, d) \& (e, f) show the top and cross-sectional surface of the parts processed by employing the same laser scan setting $(P 500 \mathrm{~W}, v 800 \mathrm{~mm} / \mathrm{s})$ for the virgin and surface-modified $\mathrm{CuCr} 1$ powder. The top surface of the part produced using the virgin $\mathrm{CuCr} 1$ powder shows unstable melt tracks along with unmolten powder particles. This indicates that the optical absorption of the powder was not sufficient to induce complete melting (refer to Supplementary Figure 2). In contrast, the top surface of the part produced using the surface-modified $\mathrm{CuCr} 1$ powder exhibits very stable melt pools, mirrored over the melt pool fusion line (indicated in Figure 7(e) using white dashed curves), 
without obvious porosity and unmolten powder particles. This indicates that the powder optical absorption of the surface-modified $\mathrm{CuCr} 1$ powder was sufficient to completely melt and fuse the powder particles, forming stable melt tracks. Within the cross-section, the part produced using the virgin $\mathrm{CuCr1}$ powder shows large, extensive, and irregular pores due to lack-of-fusion. On the contrary, the part produced using the surface-modified $\mathrm{CuCr} 1$ powder appears dense. Accordingly, the optimum LPBF setting, combining a laser power $(P)$ of $500 \mathrm{~W}$, scan speed $(v)$ of $800 \mathrm{~mm} / \mathrm{s}$, and hatch spacing (h) of $0.09 \mathrm{~mm}$, resulting in the production of dense $\mathrm{CuCr} 1$ parts $(8.83 \mathrm{~g} / \mathrm{cc}$ or relative density of $99.1 \%)$ made from the surface-modified $\mathrm{CuCr} 1$ powder, was chosen to produce industrial demonstrator parts.
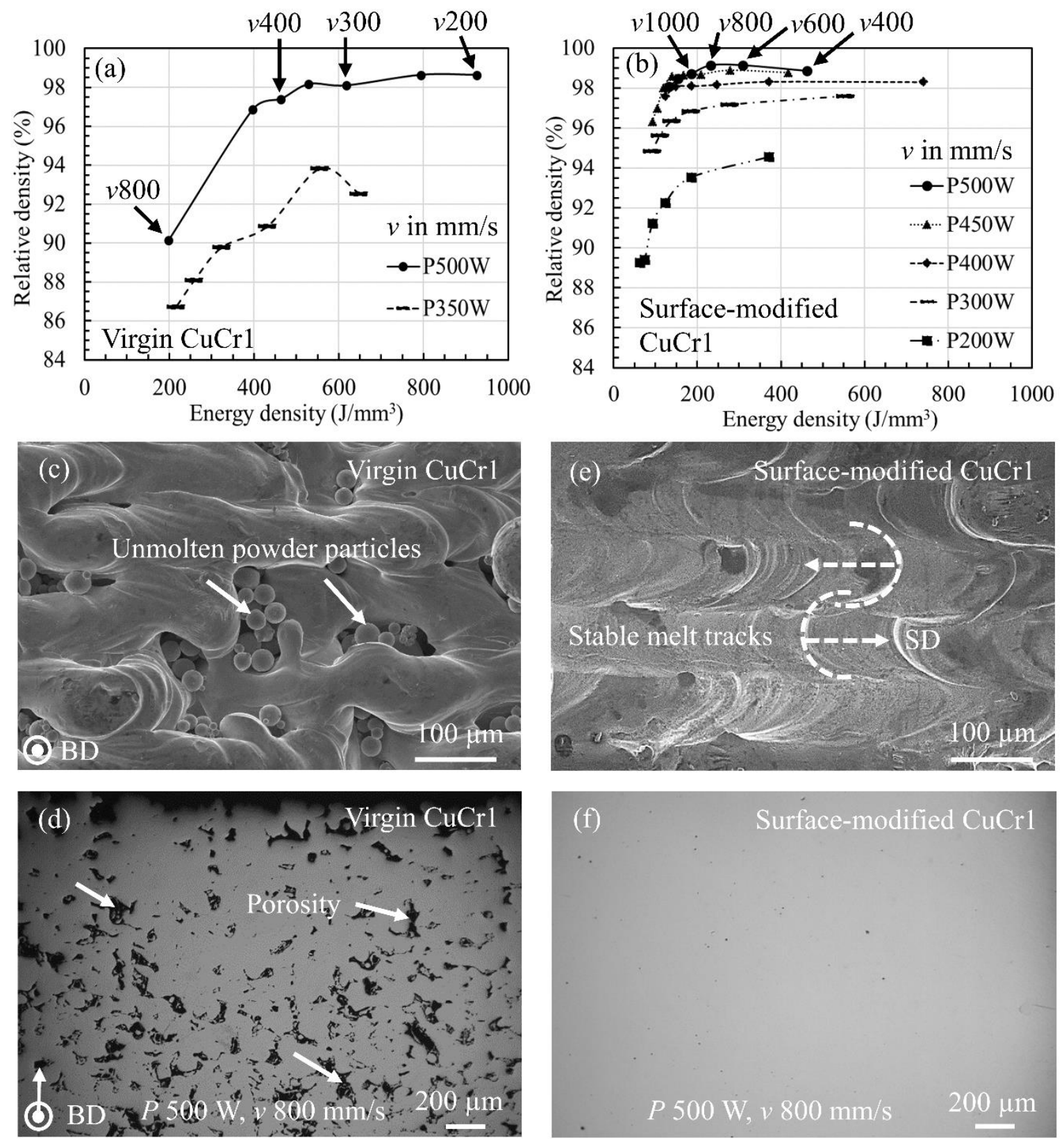

Figure 7: Evolution of the relative density of parts (\%) as a function of employed volumetric laser energy density $\left(\mathrm{J} / \mathrm{mm}^{3}\right)$ for (a) virgin, and (b) surface-modified CuCr1 powders. Note that the laser scan speeds $(v)$ are marked for the parts processed using a fixed laser power $(P)$ of $500 \mathrm{~W}$ and a hatch spacing $(h)$ of $0.09 \mathrm{~mm}$. The top surface of the parts produced at the same laser settings $(P 500 \mathrm{~W}, v$ 
$800 \mathrm{~mm} / \mathrm{s}$ ) using (c) virgin, (e) surface-modified $\mathrm{CuCr} 1$ powders. Figures (d) \& (f) show the corresponding cross-sectional surfaces for the virgin and surface-modified $\mathrm{CuCr} 1$ powder-based parts. The laser scanning direction (SD) and melt pool borders are indicated by white dashed arrows and curves, in (e), respectively.

Table 1 shows the chemical composition of the virgin and surface-modified $\mathrm{CuCr} 1$ powders along with the part fabricated using the surface-modified $\mathrm{CuCr} 1$ powder. As seen, the part produced from the surface-modified $\mathrm{CuCr} 1$ powder via LPBF contained a considerably lower amount of nitrogen $(42 \pm 28$ $\mathrm{ppm})$ compared to the initial surface-modified powder $(913 \pm 10 \mathrm{ppm})$, before LPBF processing. This indicates that the nitrogen was released during the LPBF process, and the original chemical composition of the $\mathrm{CuCr} 1$ alloy is maintained. Accordingly, the surface-modified layer can be termed as a fugitive layer, significantly improving the LPBF processability, yet not altering the original chemical composition of the alloy.

Table 1: Chemical composition of the virgin, surface-modified CuCr1 powders, and the LPBF part fabricated from the surface-modified $\mathrm{CuCr1}$ powder.

\begin{tabular}{lcccc}
\hline Alloy condition & $\begin{array}{c}\mathrm{Cr} \\
\text { (wt.\%) }\end{array}$ & $\begin{array}{c}\mathrm{N} \\
(\text { wt.\%) }\end{array}$ & $\begin{array}{c}\mathrm{O} \\
(\text { wt.\%) }\end{array}$ & $\begin{array}{c}\mathrm{Cu} \\
\text { (wt.\%) }\end{array}$ \\
\hline Virgin powder & 0.89 & 0.0008 & 0.0017 & Balance \\
Surface-modified powder & $0.89 *$ & 0.0913 & 0.0022 & Balance \\
LPBF part & 0.893 & 0.0042 & 0.0133 & Balance \\
\hline
\end{tabular}

*Considered the same value as the virgin powder, since the powder heat treatment should not add any $\mathrm{Cr}$.

\subsection{Industrial Part Fabrication, Thermal, Electrical, and Tensile Properties along with Microstructures}

The use of surface-modified $\mathrm{CuCr} 1$ powder enabled the fabrication of dense copper parts with reduced copper back-reflection levels. Accordingly, multiple industrial demonstrator parts can be manufactured having different geometry and complexity without the risk of damaging the optical mirrors of the LPBF machine. Figure 8 shows (a) a radio-frequency guide, (b) a counter flow heat exchanger, (c) a section of a heat pipe, (d) a section of a fluid mixer, (e) a section of a complex heat exchanger, all manufactured using a laser power of $500 \mathrm{~W}$, scan speed of $800 \mathrm{~mm} / \mathrm{s}$, hatch spacing of $0.09 \mathrm{~mm}$, and the powder layer thickness of $0.03 \mathrm{~mm}$. Note that the same LPBF parameter set was employed for scanning all regions (bulk, contour, support structure, up-facing surface, and down-facing surface) of the demonstrator parts. 

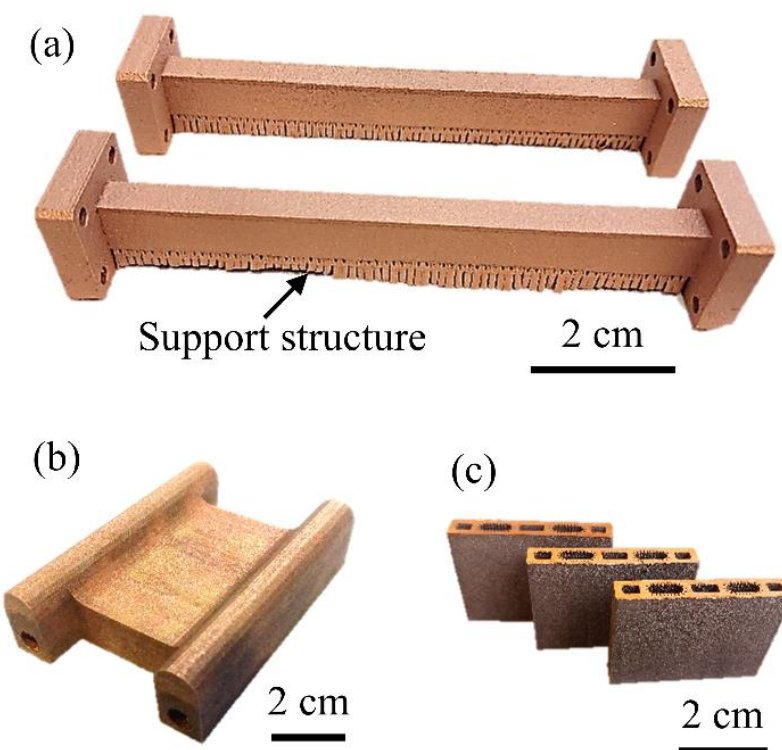

(d)

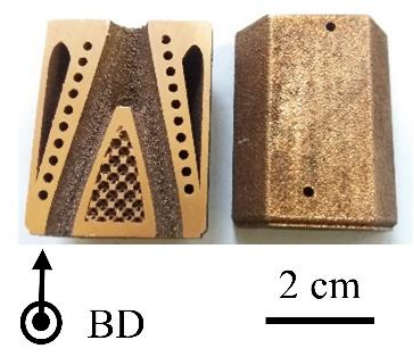

(c)

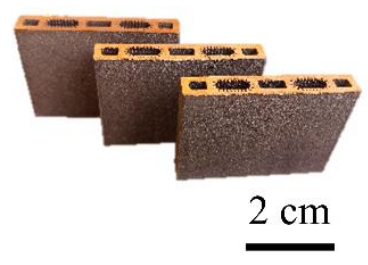

(e)

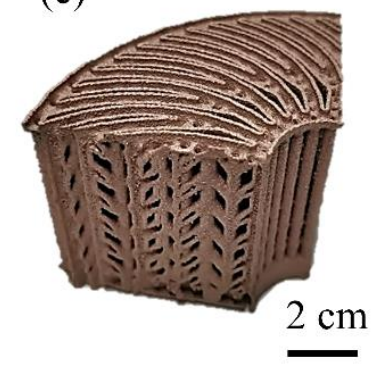

Figure 8: Successful fabrication of industrial demonstrator parts with varied geometry and complexity. All parts were fabricated using the surface-modified $\mathrm{CuCr} 1$ powder combining a laser power $(P)$ of $500 \mathrm{~W}$, a scan speed $(v)$ of 800 $\mathrm{mm} / \mathrm{s}$, a hatch spacing $(h)$ of $0.09 \mathrm{~mm}$, and a powder layer thickness $(t)$ of 0.03 $\mathrm{mm}$. The parts demonstrated in the asbuilt condition are (a) radio-frequency guide, (b) counter-flow heat exchanger, (c) section of a heat pipe, (d) section of a fluid mixer, (e) section of a complex heat exchanger. The radio-frequency guide is revealed after sand-blasting operation prior to the removal of support structures.

Table 2 summarizes the thermal, electrical, and tensile properties of the surface-modified $\mathrm{CuCr} 1$ powder-based parts, along with the reference properties of conventionally processed parts from pure $\mathrm{Cu}$ and $\mathrm{CuCr} 1$ alloy. The properties are reported for both as-built and the optimum SA+AH conditions. In general, $\mathrm{CuCr} 1$ alloys exhibit better tensile properties compared to pure $\mathrm{Cu}$, irrespective of the processing or testing conditions. However, the as-built (AB) part of $\mathrm{CuCr} 1$ alloy demonstrates substantially lower thermal and electrical conductivity values compared to pure $\mathrm{Cu}$ in soft condition. The lowest thermal and electrical conductivity values obtained for the as-built $\mathrm{CuCr} 1$ alloy could be attributed to the formation of a supersaturated solid solution of chromium and copper, represented by the absence of chromium precipitates in the as-built microstructure, shown in Figures 9 (a \& b), due to a very high cooling rate during LPBF [22]. Nevertheless, $\mathrm{CuCr} 1$ parts, after the SA+AH treatment, reveal much higher thermal, electrical, and tensile properties (except the ductility) compared to the corresponding as-built parts. This significant improvement in the properties after the $\mathrm{SA}+\mathrm{AH}$ treatment could be attributed to the typical chromium precipitation strengthening behavior of $\mathrm{CuCr}$ alloys, as shown in Figure 9 (c \& d), which also offers a purer copper matrix for better thermal and electrical conductivity compared to the as-built condition [22-24]. Note that the cross-sectional surfaces of $\mathrm{CuCr} 1$ parts do not display any difference in the porosity fraction, before and after the $\mathrm{SA}+\mathrm{AH}$ heat treatment. 
Table 2: Thermal, electrical, and mechanical properties of conventionally processed pure copper and $\mathrm{CuCr} 1$ alloy along with properties of the parts produced within this research (labeled as the modified $\mathrm{CuCr} 1$ ). The conventional properties for pure copper in soft condition are obtained from Aurubis technical data sheet - C10200 [33] and CuCr1 alloy after the optimum SA+AH treatment are achieved from the CES EduPack database by Granta Design, UK [34].

\begin{tabular}{lcccc}
\hline \multicolumn{1}{c}{ Property } & $\begin{array}{c}* \mathbf{C u} \\
(\mathbf{s o f t})\end{array}$ & $\begin{array}{c}* \mathbf{C u C r} \mathbf{c} \\
(\mathbf{S A}+\mathbf{A H})\end{array}$ & $\begin{array}{c}\text { Modified } \\
\mathbf{C u C r 1} \\
(\mathbf{A B})\end{array}$ & $\begin{array}{c}\text { Modified } \\
\text { CuCr1 } \\
(\mathbf{S A + A H})\end{array}$ \\
\hline Thermal conductivity $(\mathrm{W} /(\mathrm{m} \cdot \mathrm{K}))$ & 400 & $300-340$ & $112 \pm 1$ & $370 \pm 15$ \\
Electrical conductivity $(\mathrm{IACS} \%)$ & 100 & $75-86$ & $24 \pm 0.2$ & $81 \pm 2$ \\
Yield strength $(\mathrm{MPa})$ & 69 & $290-310$ & $183 \pm 7$ & $331 \pm 14$ \\
Tensile strength (MPa) & $179-262$ & $405-420$ & $254 \pm 5$ & $439 \pm 19$ \\
Elongation at break $(\%)$ & 35 & $14-16$ & $39 \pm 2$ & $19 \pm 3$ \\
\hline
\end{tabular}

Where,

IACS: International annealed copper standard $\left(100 \%=58 \times 10^{6} \mathrm{~S} / \mathrm{m}\right)$

AB: Parts tested in the as-built condition

$\mathrm{SA}+\mathrm{AH}$ : Parts tested after the optimum solution annealing and age hardening $(\mathrm{SA}+\mathrm{AH})$ treatment

*Properties of conventionally processed parts provided for reference
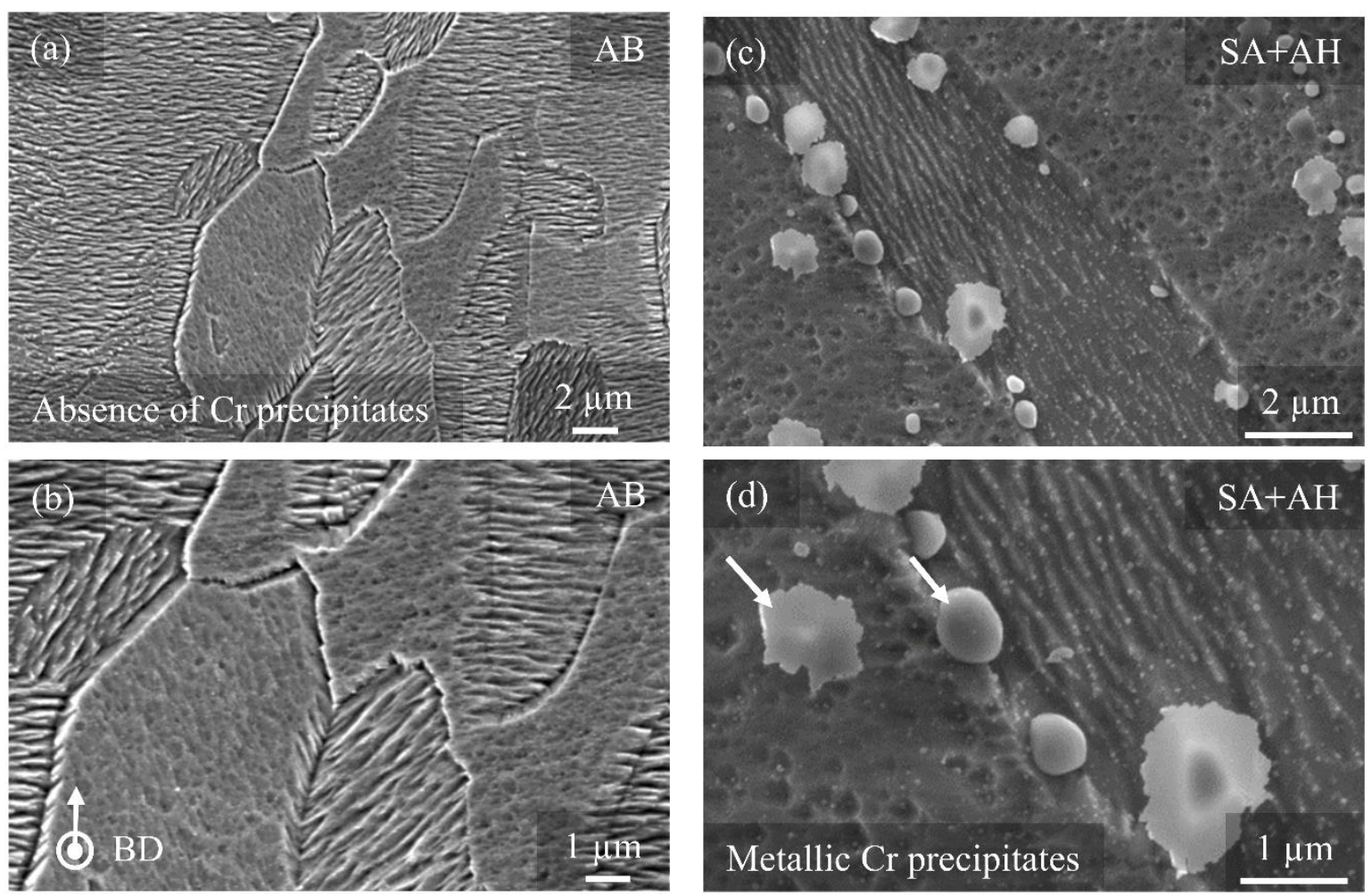

Figure 9: (a) \& (b) SEM images of the cross-sectional surface of the CuCr1 part produced using the surface-modified powder in the as-built condition. A supersaturated solid solution of the $\mathrm{Cu}-\mathrm{Cr}$ matrix, demonstrated by the absence of chromium precipitates, is realized due to a very high cooling rate during LPBF. (c) \& (d) SEM images of the part after the optimum SA+AH heat treatment displaying the presence of metallic chromium precipitates within the copper matrix, indicated by white arrows. 


\section{Discussion}

\subsection{Powder Surface Modification by Outward Diffusion of Chromium}

Figure 2 indicated that the powder optical absorption and the nitrogen content increased rapidly upon heat-treating the $\mathrm{CuCr} 1$ powder above $600^{\circ} \mathrm{C}$ in a nitrogen atmosphere. Furthermore, the XRD spectra and EDS maps in Figures (3-5) revealed the outward diffusion of chromium, forming a very thin rim around the powder particles. It was established that this rim is composed of a mixture of chromium and chromium nitrides. To explain the experimentally observed chromium diffusion trends, the diffusion depth of chromium within a copper matrix at different temperatures were theoretically calculated using Fick's second law of diffusion, given by equation (2).

$$
\frac{C(x, t)-C o}{C s-C o}=1-\operatorname{erf}\left(\frac{x}{2 \sqrt{D} \times t}\right)
$$

Fick's second law of diffusion

Where,

$C(x, t)$ : Concentration of chromium as a function of depth and time

Co: Concentration of chromium in the powder core (considered as 1 when $t=0$ )

Cs: Concentration of chromium at the powder surface (considered as 0 when $t=0$ )

$x$ : Diffusion depth (the length at which $C(x, t)=1)(\mathrm{m})$

$D$ : Diffusion coefficient at temperature $T\left(\mathrm{~m}^{2} / \mathrm{s}\right)$

$t$ : Time (s)

The diffusion constants of chromium in copper at various temperatures were obtained from Almazouzi et al. [35]. Accordingly, a graph of chromium diffusion depth, as a function of time at different heat treatment temperatures in the copper matrix, can be plotted, as shown in Figure 10. The graph demonstrates that the diffusion kinetics of chromium in the copper matrix are much faster above $600^{\circ} \mathrm{C}$. Hence, surface modification of the $\mathrm{CuCr} 1$ powder by the outward diffusion of chromium, generating a very thin rim around the powder particles could be explained by combining two aspects: (1) the faster diffusion kinetics of chromium in the copper matrix within the $600-900^{\circ} \mathrm{C}$ temperature range, and (2) the preferential outward diffusion of chromium due to exposure to the nitrogen atmosphere. In fact, at high temperatures, chromium has a high chemical affinity for nitrogen since it can form very stable chromium nitrides $\left(\mathrm{Cr}_{2} \mathrm{~N}, \mathrm{CrN}\right)$. Thus, the nitrogen atmosphere acts as the driving force for the preferential outward diffusion of chromium, forming a rim around the powder particles. 


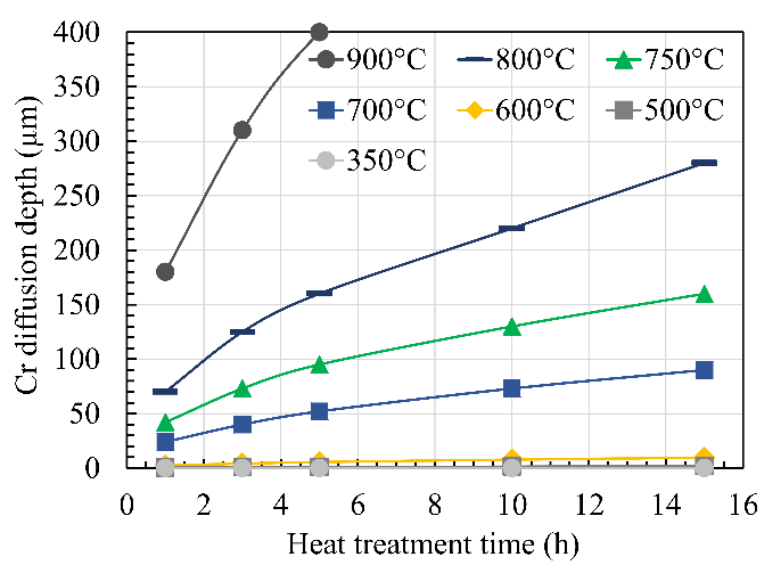

Figure 10: The diffusion depths of chromium in a copper matrix for different times at various temperatures, theoretically calculated using Fick's second law of diffusion.

\subsection{Optical Absorption and Optical Penetration Depth}

Although only a very thin surface-modified layer $(459 \pm 50 \mathrm{~nm})$ was generated, the surfacemodified $\mathrm{CuCr} 1$ powder showed a substantial improvement in the optical absorption at the fiber laser wavelength of $1080 \mathrm{~nm}$. The substantial improvement in the powder optical absorption caused by the presence of a very thin surface-modified layer could be explained by plotting both optical absorption and optical penetration depth of electromagnetic radiation within $\mathrm{Cu}, \mathrm{Cr}, \mathrm{Cr}_{2} \mathrm{~N}$, and $\mathrm{CrN}$ phases. Accordingly, the optical absorption values and the optical penetration depths were theoretically calculated using the Fresnel equation (3), and the Beer-Lambert law (Equations 4 (a \& b)), and displayed for a wavelength range of 400-1400 nm, in Figure 11(a) and (b), respectively. The optical constants (the extinction coefficients $(k)$, refractive index $(n)$, and absorption coefficients $(A)$ at different wavelengths $(\lambda)$ ), required for the calculations were obtained from the CRC handbook of chemistry [36], Aouadi et al. [37] and Novakovic et al. [38]. Note that the Fresnel equation (3) is polarizationindependent and valid when the condition $\left(n^{2}+k^{2}>1\right)$ is satisfied. For metals, this condition is generally fulfilled when $\lambda \geq 500 \mathrm{~nm}[39]$.

$A=\frac{4 n}{n^{2}+k^{2}}$

Equation (3)

Fresnel law,

Where,

A: Optical absorption

$k$ : Extinction coefficient

$n$ : Refractive index

$\begin{array}{ll}\alpha=\frac{4 \times \pi \times \kappa}{\lambda} & \text { Equation (4a) } \\ \delta p=\frac{1}{\alpha} & \text { Equation (4b) }\end{array}$

Beer-Lambert law,

Where,

$\alpha$ : Absorption coefficient $\left(\mathrm{nm}^{-1}\right)$

$\kappa$ : Extinction coefficient

$\lambda$ : Wavelength (nm) 
$\delta p$ : Optical penetration depth $(\mathrm{nm})$, where the original intensity decays to $1 / \mathrm{e}(\sim 37 \%)$ of its original value

In general, all $\mathrm{Cr}, \mathrm{Cr}_{2} \mathrm{~N}$, and $\mathrm{CrN}$ phases demonstrate higher optical absorption values compared to pure $\mathrm{Cu}$, as shown in Figure 11(a). Notably, the $\mathrm{CrN}$ phase exhibits the highest optical absorption of $\sim 78 \%$ at the fiber laser wavelength. Moreover, as shown in Figure 11(b), laser light with a $1080 \mathrm{~nm}$ wavelength can only penetrate up to the maximum depth of $50 \mathrm{~nm}$, independent on the chemistry of the material. Hence, the high optical absorption values and saturation in the optical absorption above $750^{\circ} \mathrm{C}$, obtained for the surface-modified $\mathrm{CuCr} 1$ powders could be explained by the combination of the high optical absorption values of $\mathrm{Cr}, \mathrm{Cr}_{2} \mathrm{~N}$, and $\mathrm{CrN}$ phases and the low optical penetration depth of the electromagnetic radiation at the fiber laser wavelength. Note that the laser reflectivity is mainly dependent on the optical properties of the outermost surface. Therefore, a major contribution to the optical absorption originates from the $\mathrm{CrN}$ phase, which is present at the outermost side of the surfacemodified layer, as seen in Figure 5. Furthermore, the thickness of the surface-modified layer $(459 \pm 50$ $\mathrm{nm})$ is higher than the theoretical penetration depth $(<50 \mathrm{~nm})$ of the laser light $(\lambda=1080 \mathrm{~nm})$. This indicates that the generated surface-modified layer is thick enough for the absorption of the laser energy. A slight drop was observed in the powder optical absorption from $73 \%$ to $70 \%$ at the fiber laser wavelength, while increasing the powder heat treatment temperature from $850^{\circ} \mathrm{C}$ to $900^{\circ} \mathrm{C}$, as indicated in Figure 2(a). This could be attributed to the change in powder packing density caused by the enhanced powder sintering effect and the power surface morphology (e.g., accumulations of nitrides and formation of heterogeneous films) at excessively high temperatures.
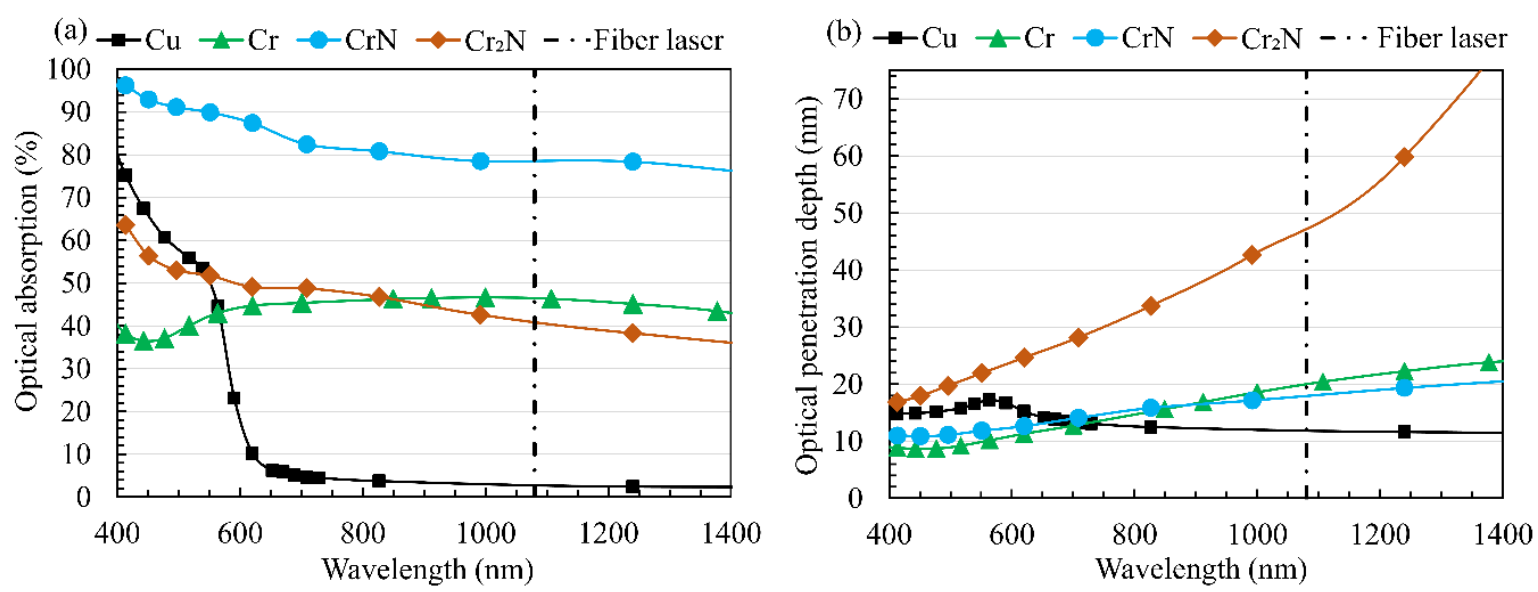

Figure 11: (a) The optical absorption values, and (b) the optical penetration depths of electromagnetic radiation (at normal incidence, i.e., $\varphi=0$ ) inside $\mathrm{Cu}, \mathrm{Cr}, \mathrm{CrN}$, and $\mathrm{Cr}_{2} \mathrm{~N}$ phases, displayed for the wavelength range of 400-1400 $\mathrm{nm}$. The optical absorption values were calculated using the Fresnel law (Equation 3), and the optical penetration depths were calculated using the Beer-Lambert law (Equations $4(\mathrm{a} \& \mathrm{~b})$ ).

\subsection{Powder Flowability and Oxygen Pickup}

Figure 6(a) showed that the surface-modified CuCr1 powder exhibits better flowability compared to the virgin $\mathrm{CuCr} 1$ powder. This could be attributed to the formation of very fine chromium nitride precipitates at the surface of the $\mathrm{CuCr} 1$ powder particles, which reduce the inter-particle cohesive forces between the copper powder particles [40,41]. Furthermore, Figure 6(b) demonstrated 
substantially lower oxygen pickup for the surface-modified $\mathrm{CuCr} 1$ powder. This beneficial effect originates from the presence of a uniform rim around the $\mathrm{CuCr} 1$ powder particles. In fact, the outer layer of this rim $(\sim 280 \mathrm{~nm})$ is composed of very stable and inert chromium nitride phases ( $\mathrm{CrN}$ and $\mathrm{Cr}_{2} \mathrm{~N}$, (Figure 5)), which prevent both the inward penetration of oxygen and the outward diffusion of chromium to form $\mathrm{Cr}_{2} \mathrm{O}_{3}$ at room temperature $[42,43]$. Since the oxygen pickup of the surface-modified $\mathrm{CuCr} 1$ powder is lower compared to the extensively oxidized virgin powder after oxygen exposure, the part properties can be enhanced by the precipitation of metallic chromium particles within the copper matrix after the application of a suitable post-heat treatment. However, this beneficial effect will be limited for the parts processed from virgin $\mathrm{CuCr} 1$ powder due to its high oxidation susceptibility [25]. It should also be noted that a low oxygen pickup during the powder storage period maintains the LPBF processing condition and part properties constant, which are essential for reliable manufacturing over time.

\subsection{LPBF Processing Behavior, Part Production, and Part Chemical Composition}

Figure 7 demonstrated substantially different LPBF processing behavior for the virgin and surface-modified $\mathrm{CuCr} 1$ powders. The surface-modified $\mathrm{CuCr} 1$ powder enabled the fabrication of dense parts using only $\sim 20 \%$ of the volumetric laser energy density required for the virgin $\mathrm{CuCr} 1$ powder (refer to Supplementary Figure 3). This drastic difference could be explained using the powder optical absorption characteristics and melt pool dynamics generated during LPBF processing of both virgin and surface-modified $\mathrm{CuCr1}$ powders.

The virgin CuCr1 powder, with D50 value of $39.9 \mu \mathrm{m}$, exhibited a low optical absorption of $34 \%$ and therefore, only a $98.6 \%$ dense part can be obtained at a very high applied volumetric laser energy density of $926 \mathrm{~J} / \mathrm{mm}^{3}$, i.e., at a low laser scan speed of $200 \mathrm{~mm} / \mathrm{s}$ and a high laser power of 500 $\mathrm{W}$. The relevant densification mechanism for the virgin, low-alloyed copper alloy powders was validated by Jadhav et al. for a CuCr0.3 alloy [25]. The authors concluded that laser scanning at a high laser power combined with a low scan speed generates deep melt pools, typically referred to as keyhole mode melt pools, which enhances multiple internal reflections of the incoming laser light within the melt pool. This feature avoids the immediate escape of the incident laser light by back-reflection and increases the absorption possibility. Accordingly, dense parts could be fabricated since the effective laser absorption (i.e., the actual laser absorption during the LPBF process) is enhanced, even though the laser absorption of the virgin powder and liquid melt is low. However, with the increase in laser scan speed and/or reduction in laser power, the possibility of having a melt pool with a keyhole is significantly reduced. This reduces multiple internal reflections of the laser light within the melt pool, and therefore, a sufficient effective laser absorption required for the complete fusion of the powder particle could not be realized. Consequently, dense parts made of virgin $\mathrm{CuCr} 1$ powder cannot be fabricated at the higher laser scan speeds $(>400 \mathrm{~mm} / \mathrm{s})$ and/or lower laser powers $(<500 \mathrm{~W})$ within the selected LPBF settings. Hence, for the virgin $\mathrm{CuCr} 1$ powder, $>98 \%$ dense parts are believed to be processed in the keyhole mode.

On the contrary, the surface-modified CuCr1 powder, with D50 value of $41 \mu \mathrm{m}$, exhibited a much higher optical absorption of $68 \%$ at the fiber laser wavelength of $1080 \mathrm{~nm}$. Hence, fully dense parts can be fabricated within a broad volumetric laser energy density range (i.e., laser scan speeds between $400-1400 \mathrm{~mm} / \mathrm{s}$, when a laser power of $500 \mathrm{~W}$ was employed). Simulation-based studies dealing with the laser-metal interaction during the LPBF process [44-47] revealed that the laser mainly irradiates the liquid melt pool and not the powder, except at a very high laser scan speeds. This could mean that the high optical absorption values obtained at room temperature for the surface-modified 
$\mathrm{CuCr} 1$ powder are no longer valid during the actual LPBF process. However, dense parts have been successfully processed via LPBF using the surface-modified $\mathrm{CuCr} 1$ powder, applying much lower volumetric laser energy density values. The densification behavior of the surface-modified powderbased parts could be explained using the melt pool dynamics that were revealed by Matthews et al. [48] and Zhirnov et al. [49], using high-speed camera imaging, during the laser metal interaction. The authors demonstrated that the powder particles from the adjoining region (labeled as the denudation zone) of the melt track are continuously pulled in to the melt pool due to the Bernoulli effect caused by the evaporation at the melt pool center, during the LPBF process. This means that, although the laser irradiates on the melt pool, there is a continuous supply of highly laser absorptive powder particles over the melt pool. Note that the amount of supplied powder particles (i.e., the length of denudation zone) can vary depending on the applied LBPB settings as well as the powder PSD and the chemical composition. As the laser with $1080 \mathrm{~nm}$ wavelength penetrates maximally up to $50 \mathrm{~nm}$ inside the material surface, it can be assumed that the majority of the laser energy is absorbed within the surfacemodified layer. As a result, the surface-modified layer is heated to a very high temperature, and subsequent fusion of the powder particle could occur by heat transfer to copper by conduction, convection, and radiation modes [50]. Moreover, the heat transfer from the surface-modified layer to the copper powder core could have also been assisted by the very high thermal conductivity of copper. Accordingly, during LPBF of the surface-modified $\mathrm{CuCr} 1$ powder, the effective optical absorption is increased mainly due to the powder surface modification. Consequently, dense parts could be fabricated even at higher laser scan speeds, i.e., even when less deep or semi-elliptical melt pools without keyhole are present that do not allow multiple internal reflections of the laser light within the melt pool. Hence, for the surface modified $\mathrm{CuCr} 1$ powder, $>98 \%$ dense parts are believed to be processed in the keyhole mode at low laser scan speeds, while in the conduction-controlled mode at high laser scan speeds. Since the optical absorption of the surface-modified $\mathrm{CuCr} 1$ powder is very high, the damage to the optical mirrors of the LPBF machine caused by copper back-reflections is successfully avoided [6]. Moreover, as the copper parts could now be fabricated at high laser scan speed (lower volumetric laser energy density or lower laser power), the laser scanning time required to fuse each layer is greatly reduced. The use of lower laser power and fiber laser-friendly copper alloy powder minimized the potential thermal lensing effect [27], and therefore, fully dense copper parts could be fabricated safely, sustainably, and reliably.

A significantly lower amount of nitrogen was measured in the LPBF fabricated part (42 \pm 28 ppm) compared to the corresponding surface-modified $\mathrm{CuCr} 1$ powder $(913 \pm 10 \mathrm{ppm})$. The expulsion of nitrogen during LPBF could be explained by a combination of the decomposition of chromium nitride $(\mathrm{CrN})$ and the low solubility of nitrogen in molten copper. As such, when a laser is irradiated on the surface-modified $\mathrm{CuCr} 1$ powder, chromium nitride is decomposed [51], and elemental chromium ( 0.89 wt.\%), and nitrogen $(913 \pm 10 \mathrm{ppm})$ are released into molten copper. Since chromium has a high solubility in liquid copper, almost all chromium ( $0.893 \mathrm{wt} . \%)$ is retained. However, nitrogen is expelled into the environment (in the form of nitrogen gas and/or nitrogen-oxide gas [52-54]) due to its very low solubility of $1.4 \mathrm{ppm}$ at $2170^{\circ} \mathrm{C}$ in liquid copper [55]. Accordingly, nitrogen expulsion can be represented using the following reactions. Note that a similar nitrogen expulsion phenomenon was also observed by Boes et al. [56] during laser powder bed fusion (LPBF) additive manufacturing (AM) of 316L stainless steel.

$$
\begin{gathered}
{[\mathrm{N}] \rightarrow 1 / 2 \mathrm{~N}_{2}(\mathrm{~g})} \\
\mathrm{N}_{\mathrm{x}}+\mathrm{O}_{\mathrm{y}} \rightarrow \mathrm{N}_{\mathrm{x}} \mathrm{O}_{\mathrm{y}}(\mathrm{g})
\end{gathered}
$$$$
\text { Reaction (1) }
$$ 


\section{Conclusions}

Surface modification of $\mathrm{CuCr} 1$ powder was successfully carried out by heat-treating $\mathrm{CuCr} 1$ powder at $750^{\circ} \mathrm{C}$, for $1 \mathrm{~h}$, in a nitrogen atmosphere. The heat treatment caused an outward diffusion of chromium from the powder core toward the surface. Consequently, a very thin rim $(459 \pm 50 \mathrm{~nm})$ composed of a mixture of metallic chromium and chromium nitrides was formed at the surface of the modified $\mathrm{CuCr} 1$ powder particles. The formation of this surface-modified layer doubled the powder optical absorption of the virgin powder from 34 to 68\%. Furthermore, the surface-modified powder effectively prevented the oxygen pickup ( $94 \mathrm{ppm}$ ) compared to the virgin $\mathrm{CuCr} 1$ powder (2200 ppm) even after storing them for twelve months at ambient conditions. The low oxygen pickup of the surfacemodified $\mathrm{CuCr} 1$ powder is mainly attributed to the outermost chromium nitride $(\sim 280 \mathrm{~nm})$ layer, inhibiting the contact of copper metal with atmospheric oxygen. This feature can substantially extend the powder storage life and recyclability.

A substantial difference in the LPBF processing behavior was observed between the virgin and surface-modified $\mathrm{CuCr} 1$ powder. For the surface-modified $\mathrm{CuCr} 1$ powder with D50 of $41 \mu \mathrm{m}$, the fabrication of dense parts was realized for a broader range of laser settings ( $v$ of $400-1400 \mathrm{~mm} / \mathrm{s}$, at $P$ of $500 \mathrm{~W}$ ). However, rather dense parts from the virgin $\mathrm{CuCr} 1$ powder, with D50 of $39.9 \mu \mathrm{m}$, can only be obtained at a very low laser scan speed $(200 \mathrm{~mm} / \mathrm{s})$, when a laser power of $500 \mathrm{~W}$ was used. The difference in LPBF behavior is attributed to the much higher powder optical absorption of the surfacemodified $\mathrm{CuCr} 1$ powder. As dense parts from the surface-modified $\mathrm{CuCr} 1$ powder can be produced at a considerably lower volumetric laser energy density (low laser power or high laser scan speed), the risk of damaging the optical mirrors of the LPBF machine due to back-reflections and the plausible thermal lensing effect producing varied part density were greatly reduced. Accordingly, industrial demonstrator parts with various dimensions and complexity were fabricated successfully without any process abnormalities and with much less energy consumption (only $20 \%$ of the laser energy that was required for the virgin powder). Moreover, the nitrogen content of $913 \pm 10 \mathrm{ppm}$, initially present in the surface-modified $\mathrm{CuCr} 1$ powder, was effectively removed during the LPBF process, though only a negligible amount of $42 \pm 28 \mathrm{ppm}$ of nitrogen was retained in the $\mathrm{CuCr} 1$ part. This demonstrated that the surface-modified layer is mainly fugitive in nature, and it does not alter the original chemical composition of the $\mathrm{CuCr} 1$ alloy. The use of a laser power below $400 \mathrm{~W}$ did not allow the production of dense parts, independent on the powder used. This is mainly attributed to the high thermal conductivity of the $\mathrm{CuCr} 1$ alloy, which quickly dissipates the absorbed heat and demands more energy for the complete fusion of the powder particles. The mechanical, electrical, and thermal properties of the fabricated parts can be tuned by applying post-heat treatments, such as solution annealing + age hardening $(\mathrm{SA}+\mathrm{AH})$. A very high thermal conductivity of $370 \pm 15 \mathrm{~W} /(\mathrm{m} \cdot \mathrm{K})$ was achieved for the $\mathrm{CuCr1}$ part after the optimum $\mathrm{SA}+\mathrm{AH}$ heat treatment.

Overall, this research offers a novel, industrially upscalable powder surface modification method, and the corresponding, fiber laser-friendly surface-modified $\mathrm{CuCr} 1$ powder with improved powder flowability and storage life. The presented surface modification method is potentially transferrable to other precipitation hardenable $(\mathrm{Cu}-\mathrm{Nb}, \mathrm{Cu}-\mathrm{Ti})$ and immiscible $(\mathrm{Cu}-\mathrm{W})$ copper alloys as well as the highly reflective silver, gold, and aluminum alloy systems, where the alloying element has an ability to form stable nitrides, carbides, or borides. Moreover, the surface-modified copper alloy powders developed using this technology could also be used in other laser-based processes, such as directed energy deposition (DED), welding, and so on. 


\section{Acknowledgments}

This project was funded by the Flanders Innovation \& Entrepreneurship Agency (Agentschap Innoveren en Ondernemen (VLAIO)) in the framework of the Strategic Basic Research (SBO) project 'MultiMet - Grant number 150010'. The authors would like to sincerely thank 3D Systems Leuven (Formerly LayerWise), Belgium, Engie Laborelec, Belgium, and SABCA, Belgium, for providing STL files for the industrial demonstrator parts. The authors are thankful to Aurubis, Belgium, for the oxygen and nitrogen content measurements, and Prof. Rajashekhara Shabadi, University of Lille, for the thermal conductivity measurements. The authors would like to acknowledge Ir. Yannis Kinds, Ir. Louca Goossens, and Prof. Brecht Van Hooreweder for installing $1 \mathrm{~kW}$ fiber laser on the LPBF machine to process copper and copper alloys.

\section{Author Contributions}

Conceptualization and realization of the powder surface modification methodology: S.D.J., Writing original draft: S.D.J., Planning design of experiments: S.D.J., K.V., Powder treatments, and characterization: S.D.J., Part treatments, and characterization: S.D.J., P.P.D., Interpretation of results: S.D.J., K.V., S.D., P.P.D., J.V.H., and J-P. K., Writing - review and editing: S.D.J., K.V., S.D., P.P.D., J.V.H., and J-P. K., Funding acquisition: K.V., S.D., J.V.H., and J-P. K.

\section{Declaration of Interest Statement}

The authors declare that a patent cooperation treaty (PCT) application has been filled on the surfacemodified copper powder and the method of production with the following details:

PCT application number: PCT/EP2019/081541

Title: Copper, gold, or silver powder and method of manufacturing such powder Filing date: November 15, 2019

\section{Data Availability}

The raw/processed data required to reproduce these findings can be made available upon request. 


\section{References}

[1] C.Y. Yap, C.K. Chua, Z.L. Dong, Z.H. Liu, D.Q. Zhang, L.E. Loh, S.L. Sing, Review of selective laser melting: Materials and applications, Appl. Phys. Rev. 2 (2015) 041101. doi:10.1063/1.4935926.

[2] R. Neugebauer, B. Müller, M. Gebauer, T. Töppel, Additive manufacturing boosts efficiency of heat transfer components, Assem. Autom. 31 (2011) 344-347. doi:10.1108/01445151111172925.

[3] D. Jafari, W.W. Wits, The utilization of selective laser melting technology on heat transfer devices for thermal energy conversion applications: A review, Renew. Sustain. Energy Rev. 91 (2018) 420-442. doi:10.1016/j.rser.2018.03.109.

[4] F. Trevisan, C. Flaviana, M. Diego, F. Paolo, Selective laser melting of chemical pure copper powders, in: Euro PM2017, 2017: pp. 1-6. doi:10.1097/00000433-198206000-00020.

[5] P.A. Lykov, E.V. Safonov, A.M. Akhmedianov, Selective Laser Melting of Copper, Mater. Sci. Forum. 843 (2016) 284-288. doi:10.4028/www.scientific.net/MSF.843.284.

[6] S.D. Jadhav, S. Dadbakhsh, L. Goossens, J.-P. Kruth, J. Van Humbeeck, K. Vanmeensel, Influence of selective laser melting process parameters on texture evolution in pure copper, J. Mater. Process. Technol. 270 (2019) 47-58. doi:10.1016/j.jmatprotec.2019.02.022.

[7] SmarTechAnalysis, Copper Additive Manufacturing 2019 - Market Database and Outlook, Crozet, VA, USA, 2019. https://www.smartechanalysis.com/reports/copper-additivemanufacturing-2019-market-database-and-outlook/.

[8] M. Sinico, G. Cogo, M. Benettoni, I. Calliari, A. Pepato, Influence of powder particle size distribution on the printability of pure copper for selective laser melting, in: 30th Annu. Int. Solid Free. Fabr. Symp., Solid Freeform Fabrication, Austin, Texas, USA, 2019: pp. 1-11.

[9] L.B. Benedetti, C.H. Ahrens, Study on selective laser melting of copper, in: $9^{\circ}$ Congr. Bras. Eng. Fabr., ABCM, Joinville, Santa Catarina, Brasil, 2017: pp. 1-10.

[10] C. Silbernagel, L. Gargalis, I. Ashcroft, R. Hague, M. Galea, P. Dickens, Electrical resistivity of pure copper processed by medium-powered laser powder bed fusion additive manufacturing for use in electromagnetic applications, Addit. Manuf. 29 (2019) 100831. doi:10.1016/j.addma.2019.100831.

[11] M. Colopi, A.G. Demir, L. Caprio, B. Previtali, Limits and solutions in processing pure Cu via selective laser melting using a high-power single-mode fiber laser, Int. J. Adv. Manuf. Technol. (2019). doi:10.1007/s00170-019-04015-3.

[12] T.-T. Ikeshoji, K. Nakamura, M. Yonehara, K. Imai, H. Kyogoku, Selective Laser Melting of Pure Copper, JOM. 70 (2018) 396-400. doi:10.1007/s11837-017-2695-X.

[13] S.D. Jadhav, J. Vleugels, J. Kruth, J. Van Humbeeck, K. Vanmeensel, Mechanical and electrical properties of selective laser-melted parts produced from surface-oxidized copper powder, Mater. Des. Process. Commun. 2 (2020). doi:10.1002/mdp2.94.

[14] Jadhav, Dadbakhsh, Vleugels, Hofkens, Puyvelde, Yang, Kruth, Humbeeck, Vanmeensel, Influence of Carbon Nanoparticle Addition (and Impurities) on Selective Laser Melting of Pure Copper, Materials (Basel). 12 (2019) 2469. doi:10.3390/ma12152469.

[15] H. Ehrenreich, H.R. Philipp, Optical properties of Ag and Cu, Phys. Rev. 128 (1962) 16221629. doi:doi.org/10.1103/PhysRev.128.1622.

[16] D. Heussen, W. Meiners, Green Light for New 3D Printing Process, 2017. https://www.ilt.fraunhofer.de/content/dam/ilt/en/documents/Publication-and- 
Press/press_release/pr2017/PR_Green_Light_for_New_3D_Printing_Process.pdf.

[17] R. Hönl, World premiere at Formnext: green laser from TRUMPF prints copper and gold, TRUMPF Glob. Press Release. (2018) 1-4.

https://www.trumpf.com/en_INT/company/press/global-press-releases/press-release-detailpage/release/world-premiere-at-formnext-green-laser-from-trumpf-prints-copper-and-gold/.

[18] M. Lang, Formalloy Making New Wave(length)s in 3D Printing, Repair and Cladding, Additivemanufacturing.Com. (2017) 1 .

http://additivemanufacturing.com/2017/09/12/formalloy-making-new-wavelengths-in-3dprinting-repair-and-cladding/ (accessed March 27, 2019).

[19] H. Siva Prasad, F. Brueckner, J. Volpp, A.F.H. Kaplan, Laser metal deposition of copper on diverse metals using green laser sources, Int. J. Adv. Manuf. Technol. (2020).

doi:10.1007/s00170-020-05117-z.

[20] K. Asano, M. Tsukamoto, Y. Sechi, Y. Sato, S. Masuno, R. Higashino, T. Hara, M. Sengoku, M. Yoshida, Laser metal deposition of pure copper on stainless steel with blue and IR diode lasers, Opt. Laser Technol. 107 (2018) 291-296. doi:10.1016/j.optlastec.2018.06.012.

[21] M. Haubold, A. Ganser, T. Eder, M.F. Zäh, Laser welding of copper using a high power disc laser at green wavelength, Procedia CIRP. 74 (2018) 446-449. doi:10.1016/j.procir.2018.08.161.

[22] S. Zhang, H. Zhu, L. Zhang, W. Zhang, H. Yang, X. Zeng, Microstructure and properties in QCr0.8 alloy produced by selective laser melting with different heat treatment, J. Alloys Compd. 800 (2019) 286-293. doi:10.1016/j.jallcom.2019.06.018.

[23] C. Wallis, B. Buchmayr, Effect of heat treatments on microstructure and properties of CuCrZr produced by laser-powder bed fusion, Mater. Sci. Eng. A. 744 (2019) 215-223. doi:10.1016/j.msea.2018.12.017.

[24] S. Uchida, T. Kimura, T. Nakamoto, T. Ozaki, T. Miki, M. Takemura, Y. Oka, R. Tsubota, Microstructures and electrical and mechanical properties of $\mathrm{Cu}-\mathrm{Cr}$ alloys fabricated by selective laser melting, Mater. Des. 175 (2019) 107815. doi:10.1016/j.matdes.2019.107815.

[25] S.D. Jadhav, S. Dadbakhsh, R. Chen, R. Shabadi, J. Kruth, J. Van Humbeeck, K. Vanmeensel, Modification of Electrical and Mechanical Properties of Selective Laser-Melted CuCr0.3 Alloy Using Carbon Nanoparticles, Adv. Eng. Mater. 22 (2020) 1900946 (1-14). doi:10.1002/adem.201900946.

[26] C. Salvan, L. Briottet, T. Baffie, P.-E. Frayssines, S. Cayre, Microstructure and properties of Copper parts obtained by Laser Powder Bed Fusion (L-PBF) process of a CuCrZr powder, in: Euro PM2019 - AM Prop. - Spec. Mater., European Powder Metallurgy Association (EPMA), 2019: pp. 1-6.

[27] L.R. Goossens, Y. Kinds, J.-P. Kruth, B. Van Hooreweder, On the influence of thermal lensing during selective laser melting, in: Solid Free. Fabr. Symp. Proc. (SFF Symp 2018), SFF, Austin; University of Texas, 2018: pp. 2267-2274.

OntheInfluenceofThermalLensingDuringSelectiveLaserMelting.pdf.

[28] S. Buls, A Smart Machine for Selective Laser Melting, KU Leuven, 2018. https://www.kuleuven.be/doctoraatsverdediging/fiches/3E11/3E110496.htm.

[29] S. Clijsters, T. Craeghs, S. Buls, K. Kempen, J.-P. Kruth, In situ quality control of the selective laser melting process using a high-speed, real-time melt pool monitoring system, Int. J. Adv. Manuf. Technol. 75 (2014) 1089-1101. doi:10.1007/s00170-014-6214-8.

[30] J.-P. Kruth, S. Dadbakhsh, B. Vrancken, K. Kempen, J. Vleugels, J. Van Humbeeck, Additive Manufacturing of Metals via Selective Laser Melting: Process Aspects and Material 
Developments, in: T. Srivatsan, T. Sudarshan (Eds.), Addit. Manuf. Innov. Adv. Appl., CRC Press, 2016: pp. 69-99.

[31] I. Miyamoto, G.A. Knorovsky, Laser microwelding, in: Y. Zhou (Ed.), Microjoining and Nanojoining, Elsevier, 2008: pp. 345-417. doi:10.1533/9781845694043.2.345.

[32] M. Naeem, Laser Processing of Reflective Materials, Laser Tech. J. 10 (2013) 18-20. doi:10.1002/latj.201390001.

[33] Aurubis, Technical data sheet - C10200 (Cu-OF ), 2018. https://www.aurubis.com/binaries/content/assets/aurubisrelaunch/files/datenblatter/cuof/c10200-cu-of-us.pdf.

[34] CES EduPack database by Granta Design, UK, (2019). https://grantadesign.com/education/ces-edupack/.

[35] A. Almazouzi, M.-P. Macht, V. Naundorf, G. Neumann, Diffusion of Manganese, Chromium, and Titanium in Single Crystalline Copper, Phys. Status Solidi. 167 (1998) 15-28. doi:10.1002/(SICI)1521-396X(199805)167:1<15::AID-PSSA15>3.0.CO;2-8.

[36] D.R. Lide, W.M.M. Haynes, G. Baysinger, L.I. Berger, H. V Kehiaian, D.L. Roth, K. Kuchitsu, D. Zwillinger, M. Frenkel, R.N. Goldberg, CRC Handbook of Chemistry and Physics, 2009-2010, 90th ed. CRC Handbook of Chemistry and Physics, 2009-2010, 90th ed . Edited by David R. Lide , Editor-in-Chief, and W. M. "Mickey" Haynes , Associate Editor (National Institute of Standards and Technology, J. Am. Chem. Soc. 131 (2009) 12862-12862. doi:10.1021/ja906434c.

[37] S.M. Aouadi, D.M. Mihut, M.L. Kuruppu, S.R. Kirkpatrick, S.L. Rohde, Spectroscopic ellipsometry measurements of chromium nitride coatings, J. Vac. Sci. Technol. A Vacuum, Surfaces, Film. 19 (2001) 2800. doi:10.1116/1.1405513.

[38] M. Novakovic, M. Popovic, Z. Rakocevic, N. Bibic, Structural, optical and electrical properties of reactively sputtered CrxNy films: Nitrogen influence on the phase formation, Process. Appl. Ceram. 11 (2017) 45-51. doi:10.2298/PAC1701045N.

[39] D. Bergström, The Absorption of Laser Light by Rough Metal Surfaces, Luleå University of Technology, 2008.

[40] L.J. Jallo, M. Schoenitz, E.L. Dreizin, R.N. Dave, C.E. Johnson, The effect of surface modification of aluminum powder on its flowability, combustion and reactivity, Powder Technol. 204 (2010) 63-70. doi:10.1016/j.powtec.2010.07.017.

[41] A. Castellanos, The relationship between attractive interparticle forces and bulk behaviour in dry and uncharged fine powders, Adv. Phys. 54 (2005) 263-376. doi:10.1080/17461390500402657.

[42] E. Huber, S. Hofmann, Oxidation behaviour of chromium-based nitride coatings, Surf. Coatings Technol. 68-69 (1994) 64-69. doi:10.1016/0257-8972(94)90139-2.

[43] J. Krzanowski, D. Foley, The Effect of Cr Content on the Oxidation Behavior of Ti-Cr-N Films, Coatings. 4 (2014) 308-319. doi:10.3390/coatings4020308.

[44] G. Fu, D. Zhang, A. He, Z. Mao, K. Zhang, Finite Element Analysis of Interaction of Laser Beam with Material in Laser Metal Powder Bed Fusion Process, Materials (Basel). 11 (2018) 765. doi:10.3390/ma11050765.

[45] A.A. Martin, N.P. Calta, J.A. Hammons, S.A. Khairallah, M.H. Nielsen, R.M. Shuttlesworth, N. Sinclair, M.J. Matthews, J.R. Jeffries, T.M. Willey, J.R.I. Lee, Ultrafast dynamics of lasermetal interactions in additive manufacturing alloys captured by in situ X-ray imaging, Mater. Today Adv. 1 (2019) 100002. doi:10.1016/j.mtadv.2019.01.001. 
[46] C. Meier, R.W. Penny, Y. Zou, J.S. Gibbs, A.J. Hart, Thermophysical Phenomena in Metal Additive Manufacturing by Selective Laser Melting: Fundamentals, Modeling, Simulation and Experimentation, Annu. Rev. Heat Transf. 20 (2017) 241-316.

doi:10.1615/AnnualRevHeatTransfer.2018019042.

[47] T. DebRoy, H.L. Wei, J.S. Zuback, T. Mukherjee, J.W. Elmer, J.O. Milewski, A.M. Beese, A. Wilson-Heid, A. De, W. Zhang, Additive manufacturing of metallic components - Process, structure and properties, Prog. Mater. Sci. 92 (2018) 112-224. doi:10.1016/j.pmatsci.2017.10.001.

[48] M.J. Matthews, G. Guss, S.A. Khairallah, A.M. Rubenchik, P.J. Depond, W.E. King, Denudation of metal powder layers in laser powder bed fusion processes, Acta Mater. 114 (2016) 33-42. doi:10.1016/j.actamat.2016.05.017.

[49] I. Zhirnov, D. V. Kotoban, A. V. Gusarov, Evaporation-induced gas-phase flows at selective laser melting, Appl. Phys. A. 124 (2018) 157. doi:10.1007/s00339-017-1532-y.

[50] Y.H. Zhou, Z.H. Zhang, Y.P. Wang, G. Liu, S.Y. Zhou, Y.L. Li, J. Shen, M. Yan, Selective laser melting of typical metallic materials: An effective process prediction model developed by energy absorption and consumption analysis, Addit. Manuf. 25 (2019) 204-217. doi:10.1016/j.addma.2018.10.046.

[51] W. Ernst, J. Neidhardt, H. Willmann, B. Sartory, P.H. Mayrhofer, C. Mitterer, Thermal decomposition routes of $\mathrm{CrN}$ hard coatings synthesized by reactive arc evaporation and magnetron sputtering, Thin Solid Films. 517 (2008) 568-574. doi:10.1016/j.tsf.2008.06.086.

[52] C.S. Howard, F. Daniels, Stability of Nitric Oxide over a Long Time Interval, J. Phys. Chem. 62 (1958) 360-361. doi:10.1021/j150561a030.

[53] W.E. Koerner, F. Daniels, The Heat of Formation of Nitric Oxide and Phosphorus Trioxide, J. Chem. Phys. 20 (1952) 113-115. doi:10.1063/1.1700148.

[54] J.A. Driscoll, Acid rain demonstration: The formation of nitrogen oxides as a by-product of high-temperature flames in connection with internal combustion engines, J. Chem. Educ. 74 (1997) 1424. doi:10.1021/ed074p1424.

[55] A.M. Mohd Noor, N.H. Muhd Nor, S. Yokoyama, Solubility of Nitrogen Gas into Molten Copper at Temperature Range of 1,993 K to 2,443 K, High Temp. Mater. Process. 36 (2017) 1035-1038. doi:10.1515/htmp-2016-0174.

[56] J. Boes, A. Röttger, L. Becker, W. Theisen, Processing of gas-nitrided AISI 316L steel powder by laser powder bed fusion - Microstructure and properties, Addit. Manuf. 30 (2019) 100836. doi:10.1016/j.addma.2019.100836. 


\section{Supplementary Figures}
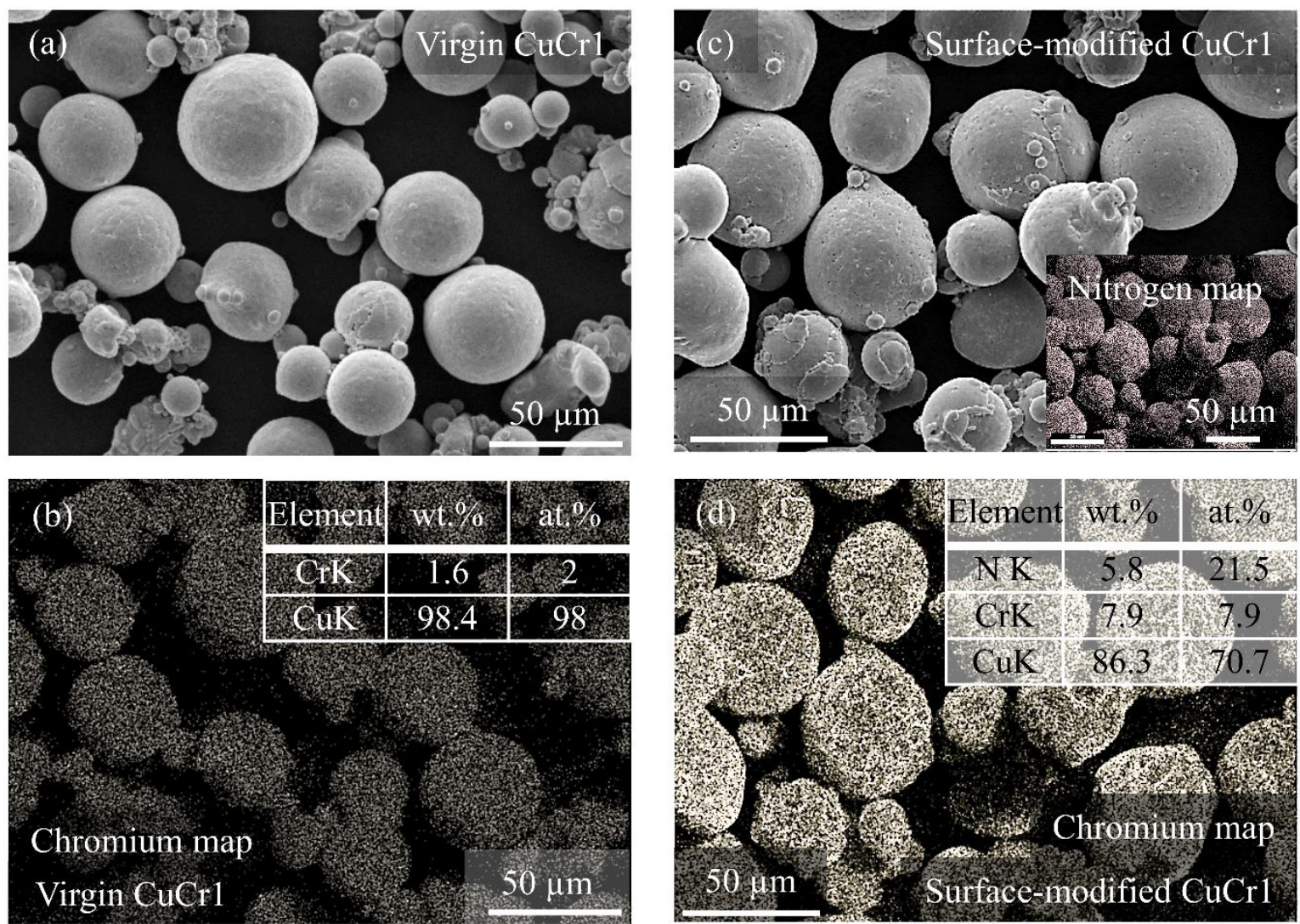

Supplementary Figure 1: (a) \& (b) SEM image and EDS map of chromium for the virgin $\mathrm{CuCr} 1$ powder. It can be seen that chromium is distributed uniformly within the powder particle and only 1.6 wt.\% of chromium can be detected at the powder surface. (c) \& (d) SEM image and EDS map of chromium for the surface-modified $\mathrm{CuCr} 1$ powder. A high amount of chromium (7.9 wt.\%) and nitrogen $(5.8 \mathrm{wt} . \%)$ is measured at the powder surface, indicating the preferential diffusion of chromium towards the powder surface, forming a chromium- and nitrogen-rich surface-modified layer. Inset in (c) shows the EDS map for nitrogen. The bright color, in the EDS maps, represents regions that are rich in chromium, and/or nitrogen, whereas the dark-colored regions are depleted of these elements. 

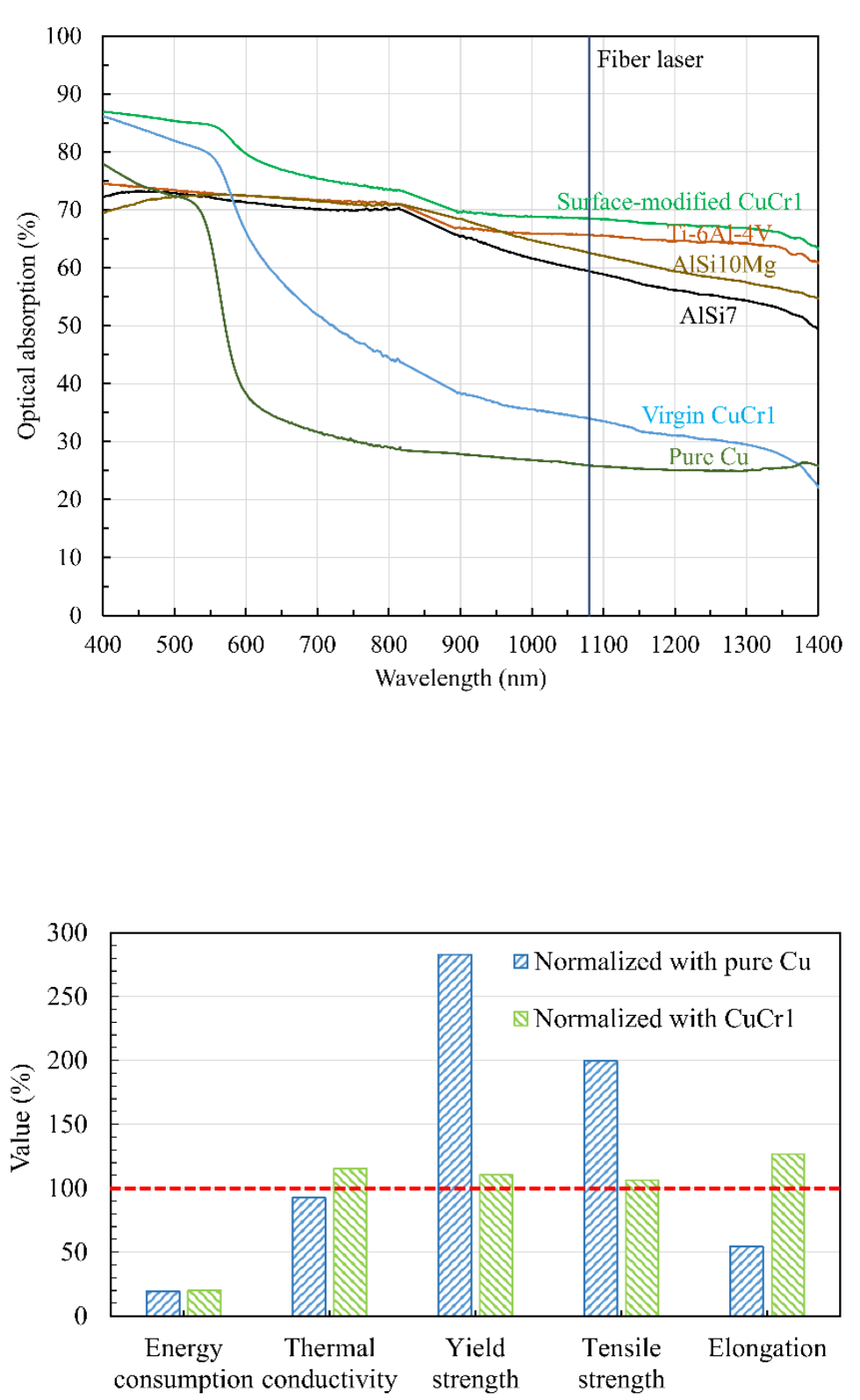

Supplementary Figure 2: The optical absorption of pure $\mathrm{Cu}$, virgin, and surface-modified $\mathrm{CuCr} 1$ alloy powders along with the commercially laser additive processable Ti-6Al-4V, AlSi10Mg, and AlSi7 alloy powders. As seen, the optical absorption of the pure $\mathrm{Cu}$ and virgin $\mathrm{CuCr} 1$ alloy powder is substantially lower, whereas it is higher for the surface-modified $\mathrm{CuCr} 1$ powder when compared to Ti-6Al-4V, AlSi10Mg, and AlSi7 alloy powders.

\section{Supplementary Figure 3:}

The properties of LPBF fabricated parts using the surface-modified $\mathrm{CuCr} 1$ powder, after the SA+AH treatment. The tensile and thermal conductivity values were normalized to conventionally processed pure $\mathrm{Cu}$ in the soft condition and $\mathrm{CuCr} 1$ alloy after the optimum $\mathrm{SA}+\mathrm{AH}$ treatment. As seen, the fabrication of parts using the surface-modified $\mathrm{CuCr} 1$ requires only $\sim 20 \%$ of energy compared to pure $\mathrm{Cu}[6]$ or virgin $\mathrm{CuCr} 1$. 